\title{
Financial Globalization and Risk Sharing: Welfare Effects and the Optimality of Open Markets
}

\author{
Charles A. Trzcinka Andrey D. Ukhov*
}

January 2006

\begin{abstract}
To study the welfare effects of investment barriers and the opening of markets to foreigners, we construct an equilibrium model of international asset pricing without agency costs that allows endogenous market participation among heterogeneous agents. Equilibrium prices and the set of participating and non-participating agents are jointly determined in equilibrium and the ability of agents to choose to participate in the market affects prices of domestic and foreign assets. We examine the welfare effects of non-participation and find that when a country moves from complete segmentation to open markets for foreigners, the cost of capital falls in the domestic market. This is consistent with empirical findings in the international asset pricing literature. Through the endogenous participation mechanism, our model is able to capture sources of economic growth. Contrary to previous models, however, we show that opening markets is not Pareto-optimal and we identify a class of domestic agents whose welfare is lower after the opening of markets. These finding have political economy interpretations and policy implications.
\end{abstract}

JEL Classification: F3; G12; G15; G31; O16.

Keywords: International asset pricing; Capital market integration and liberalization; International risk sharing; International capital market equilibrium;

${ }^{*}$ We would like to thank Andrew Abel, Gurdip Bakshi (discussant), Geert Bekaert, Craig Doidge, Janice Eberly, Albert S. "Pete" Kyle, Greg Udell, John Wald, Masahiro Watanabe, the participants of The Eleventh Assurant/Georgia Tech International Finance Conference and the participants of National Bureau of Economic Research 2005 Universities Research Conference: Structural Changes in the Global Economy: Implications for Monetary Policy and Financial Regulation for helpful discussions and comments. Charles A. Trzcinka is James and Virginia Cozad Chair and Professor of Finance, Kelley School of Business, Indiana University, E-mail: ctrzcink@indiana.edu Andrey D. Ukhov, Assistant Professor of Finance, Kelley School of Business, Indiana University, 1309 East 10th Street, Bloomington, IN 47405. Telephone: 812-855-2698, Fax: 812-855-5875. E-mail: aukhov@indiana.edu 


\title{
Financial Globalization and Risk Sharing: Welfare Effects and the Optimality of Open Markets
}

\begin{abstract}
To study the welfare effects of investment barriers and the opening of markets to foreigners, we construct an equilibrium model of international asset pricing without agency costs that allows endogenous market participation among heterogeneous agents. Equilibrium prices and the set of participating and non-participating agents are jointly determined in equilibrium and the ability of agents to choose to participate in the market affects prices of domestic and foreign assets. We examine the welfare effects of non-participation and find that when a country moves from complete segmentation to open markets for foreigners, the cost of capital falls in the domestic market. This is consistent with empirical findings in the international asset pricing literature. Through the endogenous participation mechanism, our model is able to capture sources of economic growth. Contrary to previous models, however, we show that opening markets is not Pareto-optimal and we identify a class of domestic agents whose welfare is lower after the opening of markets. These finding have political economy interpretations and policy implications.
\end{abstract}




\section{Introduction}

The impact of opening a country's capital markets to foreign investors, often defined as "financial globalization," has been the subject of research in financial economics for over thirty years. In standard economic models, the opening of markets has major benefits. It enables investors worldwide to share risks better, it enhances capital flow to projects where its productivity is highest and it allows countries to reap the benefits of their comparative advantages. Yet the empirical evidence on these benefits is mixed and the impact of financial globalization is a subject of heated political debate. In contrast to the predictions of standard economic theory, economists have found considerable evidence of "home bias" where an investor's portfolio is disproportionately weighted towards stocks of his home country. Empirical evidence also shows that a country's investment is closely tied to the amount it saves, that a country factor is the most important factor in asset returns and that a firm's country of origin is a more important determinant of its financial policies than its industry. The political support of open markets is undermined not only by the self interest of groups who will lose to foreign competitors but by arguments that foreign investors may force domestic investors out from some assets and increase their risk exposure. Further political arguments are made that foreign investors will increase a country's exposure to external shocks. ${ }^{1}$

The classic international asset pricing models are not well-equipped to deal with this evidence and these arguments. Black (1974), Stulz (1981a, 1981b), Errunza and Losq(1985), Eun and Janakiramanan (1986) and Alexander, Eun and Janakiramanan (1987) incorporate investment restrictions and focus on the portfolio problem of domestic and foreign investors, asset pricing and

\footnotetext{
${ }^{1}$ Rajan and Zingales (2003) document reversals in financial development and study empirically why some countries become more open to capital flows than others, or open up at some times rather than at others. Stulz (2005) contains a review of pros and cons of liberalization. See also Wincoop (1994). See Schmukler (2003) and references therein for a discussion of benefits and risks of financial globalization. Bhagwati (1998) and Rodrik (1998, 2000) argue that there are compelling cases for maintaining capital controls. In contrast to general perceptions that markets are becoming more integrated, the results in Bekaert and Harvey (1995) suggest that some countries have become less integrated into the world market over time. Measurement theory developed by Chen and Knez (1995) offers a method to measure degree of integration. Kaminsky and Schmukler (2004) document that many countries have undergone several liberalization reversals, particularly following currency crises. Clarke, Cull, Peria, and Sánchez (2003, 2004) document the magnitude of foreign bank presence in developing countries and investigate whether foreign bank entry is beneficial for developing countries. See Goetzmann, Ukhov, and Zhu (2001) for a discussion of China's case.
} 
the cost of capital. ${ }^{2}$ In practice these barriers can take many forms including ownership restrictions, differential tax rates for foreigners, currency conversion restrictions and high transactions costs. In the models, the effect of the assumed barriers are to effectively segment the markets so foreign and domestic investors face different investment opportunities. ${ }^{3}$

The evidence and political debates suggest that the opening of markets causes significant welfare effects in a closed economy but classical asset pricing models were not designed to address welfare effects of investment barriers. Subrahmanyam (1975a, 1975b) recognized this limitation and constructs models that study the pricing and welfare effects of fully integrating a completely segmented market. He shows that international capital market integration is Pareto Optimal the welfare of individuals in the integrated economies never declines and will generally improve. Errunza and Losq (1989) develop a multi-country framework with homogeneous agents in each country. They, too, show that removal of investment barriers generally leads to an increase in the aggregate market value of the affected securities and all investors will favor market integration.

However, these models and all international asset pricing theories take barriers as given. The theories do well explaining asset prices and the cost of capital when markets are liberalized and they have guided numerous empirical studies. Their shortcoming is that models based on homogenous agents and exogenous investment barriers are not designed to assess the welfare effects of investment barriers. They cannot provide conditions for the existence of barriers within a rational economic framework. The empirical evidence and the political debates suggest that at least some barriers to capital flows are part of a rational economic system and that the decision to remove barriers is

\footnotetext{
${ }^{2}$ Other important theoretical studies are: Basak (1996), Bennett and Young (1999), Grauer, Litzenberger, and Stehle (1976), Obstfeld (1994), Dumas and Uppal (2001). For a corporate finance perspective see Adler and Dumas (1975), Adler and Dumas (1983), Senbet (1979), Errunza and Senbet (1981), Foerster and Karolyi (1999), Stulz (1999b), Stulz and Wasserfallen (1995), Errunza and Miller (2000). Stapleton and Subrahmanyam (1977) use numerical examples to study the effects of market segmentation on asset prices, cost of capital, and corporate finance decisions.

${ }^{3}$ Stulz (1981b) studies the implications of barriers to international investment for the composition of optimal portfolios at home and abroad. In the Stulz model domestic investors face barriers to international investment in the form of taxes, whereas foreign investors face no barriers to international investment. In the model some risky foreign assets can be nontraded, in the sense that they are not held by domestic investors and would not be held if their expected return changed slightly. For a discussion of foreign investment income taxation see also Feldstein and Hartman (1979).
} 
endogenous. By not being able to address the issue of endogeneity, existing models are limited in the guidance they can provide. A new class of models is needed to help identify potential sources of economic opposition to the liberalization process.

A new international asset pricing theory is also needed to model the sources post-liberalization economic growth, identified by the empirical studies (see, e.g. Bekaert, Harvey, Lundblad 2004). Classical asset pricing models, including the Capital Asset Pricing Model (CAPM) and its international counterpart, International CAPM, and the Consumption-based versions, strictly speaking, do not model growth. The classical asset pricing models keep the composition of assets fixed. They can generate comparative static results and predict that the cost of capital will fall when a market becomes integrated, but CAPM-based models do not identify new projects that are financed because of the lower cost of capital.

We develop a new modeling approach that allows heterogeneous agents to endogenously choose whether to participate and we study the welfare effects of opening markets to foreigners. Our modeling technique allows us to focus on understanding the opposing rational economic forces that act in an economy that opens to foreign investment. ${ }^{4}$ We assume there are two economies, domestic and foreign, each composed of a continuum of agents who are different in their risk exposure and endowment income. There are no agency costs or transactions costs in this model except for a participation cost foreign and domestic investors pay to enter risky asset market. As is standard in the Consumption Capital Asset Pricing Models, agents trade in a two-date model because they have a motive to hedge the risk present in their endowment income. A risk-free bond is available to all agents without any participation cost. An agent must pay a fixed participation cost to trade risky assets and once the fee is paid the agent gains access to all risky assets. The set of agents who decide to pay the fee and participate in the risky asset market is endogenously determined in equilibrium as is supply and demand of the risky asset, market clearing prices and the welfare of all agents. Endogenous decision to participate in the risky asset market is important new feature of the model. In short, the model is a general equilibrium framework that allows us to study the

\footnotetext{
${ }^{4}$ The forces, discussed in detail later, reflect changes in supply and demand for domestic assets. When foreign investors enter domestic security market they increase demand for domestic risky assets and supply capital to new projects. Domestic agents who sell risky assets and receive capital, benefit. At the same time, domestic agents who purchase domestic assets now need to compete with the foreign investors, and may see their welfare fall under partial liberalization when compared to complete segmentation.
} 
behavior of these variables simultaneously.

The model builds on the foundation provided by the existent theoretical and empirical work. Many important results have been obtained in the literature under the guidance of the international CAPM. It is desirable that a new model aimed at explaining investment barriers be consistent with the previous findings. Therefore, we do not depart entirely from the CAPM framework and are able to obtain standard Consumption CAPM results as a special case of our model. Similar to other models of international asset pricing, we show that financial globalization, that is, opening a market to foreign investors generally reduces the country's cost of capital even though we do not allow domestic investors to trade in the foreign market. This is the consistent finding of empirical work. Bekaert and Harvey (2000), Henry (2000), Kim and Singal (2000) and Patro and Wald (2004) find that stock market liberalization causes an increase in stock prices and a fall in cost of capital. ${ }^{5}$ Peria and Mody (2004) find that liberalization reduces the cost of capital supply by banks. In our model, issuers of securities benefit two ways-the securities sell for higher prices after the market opens and there are more participants who issue securities so capital flows increase. Projects that could not be financed under complete segmentation are financed when markets open to foreigners because foreign investors purchase domestic assets.

In contrast to previous models, motives to trade and participate are endogenous and we can consider the change in welfare of the domestic agents who purchase domestic risky assets to hedge endowment income. The decision to open markets impacts risk-sharing arrangements in the economy and affects asset prices, as well as welfare of agents. The benefit of higher prices for issuers for opening the market is a cost for domestic investors who experience a welfare loss. Participation in the market for risk-sharing becomes more expensive and some agents decide not to participate.

Existing finance theories make predictions about changes in cost of capital in a country that liberalizes its capital market. By developing a model with risky endowment income, heterogeneous agents and endogenously determined participation, we are able to link the existing theories of international asset pricing to the literature on risk sharing. The findings of this paper highlight the effect of financial globalization on risk-sharing and we show that:

\footnotetext{
${ }^{5}$ Patro and Wald (2004) use firm level data from 18 emerging markets. They find that firms' stock returns increase during liberalization and that a majority of firms have lower mean returns after liberalization. In the 36-month period starting three and a half years after the liberalization date, firm returns decrease on average by a highly significant 2.88 percent per month.
} 
- Removal of barriers changes the composition of investors who demand risky assets causing prices and the cost of capital to change.

- Removal of barriers may make it more expensive for some domestic agents to participate in risk-sharing offered by risky domestic assets and will lead to a decrease in their welfare.

- Investment barriers may be welfare enhancing for a country and the decision to maintain barriers may be an endogenous, rational economic decision and not the result of agency costs or political failure.

- The argument for liberalization may be refined by identifying the set of agents who find risk sharing attractive after markets open.

- Since the decision to maintain investment barriers is endogenous, the timing of liberalization in our model will not be random and will be a function of endowments, prices and riskexposure. This suggests that accounting for endogeneity is especially important in empirical work.

- Our model provides a rational explanation for the historical evidence of liberalization and reversal of liberalization found by Rajan and Zingales (2003).

If liberalization and integration are as important as classical models suggest, then it is crucial to understand the potential negative effects of the process. Our model suggests that improving domestic capabilities for risk-sharing may be a critical factor in mitigating the negative impact of financial globalization on some domestic consumers. ${ }^{6}$

This paper is organized as follows. General theory of international asset pricing with endogenous participation is developed in Section 2. A class of single risk factor economies is studied in Section 3. Section 3.3 is focused on welfare analysis. It is shown in this section that partial liberalization is not necessarily a Pareto optimal policy. It is also shown that aggregate domestic welfare may be lower under liberalization than under complete segmentation. Section 4 describes policy implications of our findings and concludes.

\footnotetext{
${ }^{6}$ Kaminsky and Schmukler (2004) examine the short- and long-run effects of financial liberalization on capital markets. Their results indicate that financial liberalization is followed by more pronounced boom-bust cycles in the short run. However, financial liberalization leads to more stable markets in the long run.
} 


\section{General Theory}

First, we develop a general theory of international asset pricing with endogenous equity market participation. There are two sets of agents in the model, foreign investors (set $\mathcal{F}$ ), and domestic investors $($ set $\mathcal{D})$. We endow each space with a measure $\mathbb{P}^{d}$ and $\mathbb{P}^{f}$, respectively, that satisfy $\mathbb{P}^{d}(\mathcal{D})=1$ and $\mathbb{P}^{f}(\mathcal{F})=1$. This is equivalent to viewing each element of $\mathcal{F}$ or $\mathcal{D}$ as a type, and the measures $\mathbb{P}^{d}$ and $\mathbb{P}^{f}$ as probability distributions over all possible types. This is a one-period model. Agents are endowed with initial wealth and receive an uncertain endowment income at the end of the period. Agents solve a consumption-portfolio problem to maximize expected lifetime utility of consumption. Consumption takes place at the beginning of the period (time 0) and at the end of the period (time 1). Agents have negative exponential utility of consumption (CARA preferences). There are two sets of assets, foreign and domestic. The assets are defined through their expected payoffs at time 1, variance-covariance matrix of asset payoffs, and covariance between the endowment income and asset payoff. Parameters of the model are summarized in Table 1. All random variables are assumed to be jointly Normally distributed.

In the model, segmented capital market and partially liberalized capital market are different with respect to the sets of assets available to different investors. Under the benchmark case of complete segmentation foreign investors have access to foreign assets only and domestic investors have access to the domestic assets only. Under partial liberalization, the domestic asset market becomes open to foreign investors; domestic investors do not have access to foreign securities. We begin with the case of complete segmentation. 
Table 1

Variables and Parameters of the Model

$\Sigma_{d} \quad$ Variance-covariance matrix for domestic assets.

$\Sigma_{f} \quad$ Variance-covariance matrix for foreign assets.

$\Sigma_{d, f} \quad$ Matrix of covariances between domestic and foreign assets.

$\overline{\mathbf{z}}_{d} \quad$ Vector of expected payoffs on domestic assets.

$\overline{\mathbf{z}}_{f} \quad$ Vector of expected payoffs on foreign assets.

$\mathcal{D} \quad$ The set of all domestic investors.

$\mathcal{F} \quad$ The set of all foreign investors.

$W_{0}^{h} \quad$ Initial (time 0) wealth of investor $h$.

$\tilde{e}^{h} \quad$ Time 1 random endowment payoff for agent $h$.

$\bar{e}^{h} \quad$ Expected time 1 endowment payoff for agent $h$.

$\sigma_{e^{h}}^{2} \quad$ Variance of terminal endowment for agent $h$.

$\boldsymbol{\sigma}_{e, d}^{h} \quad$ Vector of covariances between the endowment payoff and domestic assets.

$\boldsymbol{\sigma}_{e, f}^{h} \quad$ Vector of covariances between the endowment payoff and foreign assets.

$k_{d} \quad$ Fixed cost that domestic investors $(h \in \mathcal{D})$ must pay to hold domestic securities.

$k_{f} \quad$ fixed cost that foreign investors $(h \in \mathcal{F})$ must pay to hold foreign securities.

\subsection{Complete Segmentation}

Under complete segmentation foreign investors only hold foreign stocks and the risk-free asset and domestic investors trade only in domestic risky securities and domestic risk-free asset. In this case domestic investors set prices in the domestic market, and foreign investors set prices of the foreign assets. In our model, both foreign and domestic investors first have to make a participation decision. An investor may decide to pay the fixed cost, $k_{d}$ for a domestic investor or $k_{f}$ for a foreign investor, and invest in the risky assets and the risk free asset available in his market. For tractability it is assumed that all domestic investors face the same cost $k_{d}$ and all foreign investors face identical 
cost, $k_{f} \cdot{ }^{7}$ These are lifetime costs of being an investor in equity market. The costs $k_{d}$ and $k_{f}$ reflect economic and technological development (see Stulz and Wasserfallen (1995) and Basak and Cuoco (1998) for a discussion of similar deadweight costs). Alternatively, an investor may decide not to pay the fee and to invest in the risk-free bond only. The decision to participate is endogenous.

Subscript ${ }_{S}$ denotes the values under complete segmentation, and subscript $m$ stands for either domestic market $(m=d)$ or the foreign market $(m=f)$ and is used for brevity.

A domestic investor $(h \in \mathcal{D}$ and $m=d)$ solves consumption-portfolio problem considering investment in domestic assets only. Variables that describe the opportunity set for domestic investor are the vector of asset expected payoffs $\overline{\mathbf{z}}_{d}$, variance-covariance matrix for domestic assets $\Sigma_{d}$, and vector of covariances between the endowment payoff and domestic assets, $\sigma_{e, d}^{h}$. Investor takes equilibrium prices of risky domestic assets, $\mathbf{p}_{S, d}$, and the domestic interest rate, $R_{d}$, as given.

A foreign investor $(h \in \mathcal{F}$ and $m=f)$ solves consumption-portfolio problem considering investment in foreign assets only. His investment opportunity set is described by $\overline{\mathbf{z}}_{f}, \Sigma_{f}$, and $\boldsymbol{\sigma}_{e, f}^{h}$. Investor takes equilibrium prices of risky foreign assets, $\mathbf{p}_{S, f}$, and the foreign interest rate, $R_{f}$, as given.

Each agent makes an endogenous participation decision. To solve the participation decision problem of an individual agent $h$, calculate the consumption - portfolio problem under entry and non-entry. If the derived utility of wealth is higher under participation, investor will choose to pay fixed amount and invest in risky assets. The participant in the risky asset market (either domestic or foreign) solves the expected utility maximization problem

$$
\begin{aligned}
J_{S, m}^{p}\left[W_{0}^{h}\right] & =\max _{c_{S, m, 0}^{h}, \boldsymbol{\theta}_{S, m}^{h}, \theta_{S, m, 0}^{h}}\left\{-e^{-a c_{S, m, 0}^{h}}-\delta \mathbb{E} e^{-a \widetilde{c}_{S, m, 1}^{h}}\right\} \\
W_{0}^{h} & =c_{S, m, 0}^{h}+\mathbf{p}_{S, m}^{\prime} \cdot \boldsymbol{\theta}_{S, m}^{h}+k_{m}+\theta_{S, m, 0}^{h} / R_{m} .
\end{aligned}
$$

with respect to three decision variables: time 0 consumption $c_{S, m, 0}^{h}$; time 0 post-trade holdings of risky assets $\boldsymbol{\theta}_{S, m}^{h}$ in the investor's respective market; and time 0 investment in the bond, $\theta_{S, m, 0}^{h}$. The dimension of vector $\boldsymbol{\theta}_{S, m}^{h}$ equals the number of assets in the economy $m$. The superscript $p$

\footnotetext{
${ }^{7}$ It is possible to modify the analysis so that domestic investors have a fixed cost $k_{d}^{d}$ when they invest in domestic risky assets and a different fixed cost $k_{f}^{d}$ is they want to invest in foreign risky assets. Then, a domestic investor who holds both domestic and foreign stocks would pay a total fixed fee of $k_{d}^{d}+k_{f}^{d}$. Similarly, under this model specification, a foreign investor would face fixed cost $k_{f}^{f}$ when investing in foreign risky assets and $k_{d}^{f}$ when investing in domestic risky assets.
} 
denotes the values under the optimal policy for a participant and superscript $n$ for non-participant. Solution to the optimization problem, including the optimal consumption-portfolio policy, is given in the Appendix. The solution gives the following expression for the indirect utility function of a participant,

$$
\begin{aligned}
J_{S, m}^{p}\left[W_{0}^{h}\right]= & -\left(1+R_{m}\right) \delta . \\
& \exp \left\{-\frac{a}{1+R_{m}}\left[\bar{e}^{h}+R_{m}\left(W_{0}^{h}-k_{m}\right)+\frac{R_{m} \ln \delta R_{m}}{a}-\frac{a \sigma_{e^{h}}^{2}}{2}+\frac{S_{S, m}^{2}(h)}{2 a}\right]\right\},
\end{aligned}
$$

where $S_{S, m}^{2}(h) \equiv\left(\overline{\mathbf{z}}_{m}-R_{m} \cdot \mathbf{p}_{S, m}-a \boldsymbol{\sigma}_{e, m}^{h}\right)^{\prime} \Sigma_{m}^{-1}\left(\overline{\mathbf{z}}_{m}-R_{m} \cdot \mathbf{p}_{S, m}-a \boldsymbol{\sigma}_{e, m}^{h}\right)$ is the square of the generalized Sharpe ratio, as discussed in more detail below. It measures the attractiveness of the investment opportunity set for investor $h$. The opportunity set is characterized by $\overline{\mathbf{z}}_{m}, \Sigma_{m}^{-1}$, and vector of covariances $\boldsymbol{\sigma}_{e, m}^{h}$. It is clear from the above expression that the effect of investment opportunity set characteristics on investor utility is fully captured by $S_{S, m}^{2}(h)$.

Non-participant in the risky asset market chooses the level of current consumption and invests the remainder of wealth into the riskless bond to solve,

$$
\begin{aligned}
J_{S, m}^{n}\left[W_{0}^{h}\right] & =\max _{c_{S, m, 0}^{h}, \theta_{S, m, 0}^{h}}\left\{-e^{-a c_{S, m, 0}^{h}}-\delta \mathbb{E} e^{-a \widetilde{c}_{S, m, 1}^{h}}\right\}, \\
\text { s.t. } \quad W_{0}^{h} & =c_{S, m, 0}^{h}+\theta_{S, m, 0}^{h} / R_{m} .
\end{aligned}
$$

A non-participant allocates wealth $W_{0}^{h}$ between initial consumption $c_{S, m, 0}^{h}$ and the purchase of $\theta_{S, m, 0}^{h}$ units of the risk-free bond. Terminal consumption of a non-participant equals $\widetilde{c}_{S, m, 1}^{h}=\widetilde{e}^{h}+\theta_{S, m, 0}^{h}$. Solution to the optimization problem, including the optimal consumption-portfolio policy, is given in the Appendix. The expression for a non-participant's derived utility of wealth function is

$$
J_{S, m}^{n}\left[W_{0}^{h}\right]=-\delta\left(1+R_{m}\right) \exp \left[-\frac{a}{1+R_{m}}\left[\bar{e}^{h}+R_{m} W_{0}^{h}+\frac{R_{m} \ln \delta R_{m}}{a}-\frac{a}{2} \sigma_{e_{m}^{h}}^{2}\right]\right] .
$$

Non-participants bear all the income uncertainty, the variance of terminal consumption equals the variance of time 1 income. For a participant, the variance of terminal consumption is a function of the variance of endowment income, the variance of the optimal portfolio of risky assets, and the covariance between the two. Participants pay a fee to gain an opportunity to construct an optimal portfolio and adjust the expected value and uncertainty of the terminal consumption. 


\subsubsection{Participation problem}

To decide whether to pay the participation fee and invest in risky assets domestic and foreign investors compare expected utility under entry and non-entry. This comparison yields the following participation criterion.

Theorem 1 (Participation Criterion) The investor will pay the participation fee $k_{m}$ and invest in risky assets available on his market when

$$
\frac{1}{2 a}\left(\overline{\mathbf{z}}_{m}-R_{m} \mathbf{p}_{S, m}-a \boldsymbol{\sigma}_{e, m}^{h}\right)^{\prime} \Sigma_{m}^{-1}\left(\overline{\mathbf{z}}_{m}-R_{m} \mathbf{p}_{S, m}-a \boldsymbol{\sigma}_{e, m}^{h}\right)>R_{m} k_{m}
$$

and is indifferent between participation and non-participation if the relation holds with an equality.

The quantity on the left-hand-side has a natural interpretation as a generalization of Sharpe's performance measure. It is well known that in an economy with negative exponential utility and Normally distributed payoffs agent's portfolio problem is equivalent to selecting a vector of portfolio

holdings $\boldsymbol{\theta}_{S, m}^{h}$ to maximize the certainty equivalent $\mathbb{E}\left[\widetilde{c}_{S, m, 1}^{h}\right]-\frac{a}{2} \operatorname{Var}\left[\widetilde{c}_{S, m, 1}^{h}\right]$. The solution is given by $\boldsymbol{\theta}_{S, m}^{h}=\frac{1}{a} \Sigma_{m}^{-1}\left(\overline{\mathbf{z}}_{m}-R_{m} \mathbf{p}_{S, m}-a \boldsymbol{\sigma}_{e, m}^{h}\right)$. The optimal value of the criterion function is increasing in the quantity $S^{2}$,

$$
S_{S, m}^{2}(h) \equiv\left(\overline{\mathbf{z}}_{m}-R_{m} \mathbf{p}_{S, m}-a \boldsymbol{\sigma}_{e, m}^{h}\right)^{\prime} \Sigma_{m}^{-1}\left(\overline{\mathbf{z}}_{m}-R_{m} \mathbf{p}_{S, m}-a \boldsymbol{\sigma}_{e, m}^{h}\right) .
$$

This is a natural generalization of Sharpe's performance measure to the case of multiple assets and risky agent-specific endowment. It depends on the parameters that characterize the set of investment opportunities. These are: expected payoffs, $\overline{\mathbf{z}}_{m}$, equilibrium asset prices $\mathbf{p}_{S, m}$, and covariance matrix $\Sigma_{m}$. It also depends on $\boldsymbol{\sigma}_{e, m}^{h}$, the vector of covariances that determine income hedging opportunities available to the investor. The measure is agent-specific, because it takes into account covariances between risky assets in the economy and the agent's random endowment income.

Note that $S_{S, m}^{2}(h)$ is unitless, so the participation criterion is independent of wealth. This is so because negative exponential utility has no wealth effect. Regardless of wealth, a participant holds the same dollar amount of risky assets, so wealthier investors are not more likely to participate.

Participation criterion (1) highlights several important features of the market segmentation problem. If markets are liberalized, then investors gain access to assets previously unavailable 
to them. Then quantity on the left-hand-side of the participation criterion is changed. ${ }^{8}$ It is affected by the expected returns on the new assets and by the changes in the covariance structure of the economy. There are additional effects, however, because financial liberalization also changes the prices of risky securities. This is different from the canonical mean-variance international portfolio problem. In the classical mean-variance analysis addition of new assets always increases the Sharpe ratio of the market portfolio. Therefore, in such models investors benefit from international financial liberalization. When everyone holds the market portfolio addition of new assets improves investment opportunities. Equilibrium analysis presented in this paper, is different because financial liberalization changes the set of participating agents. This affects the demand for assets and causes changes to the asset prices.

\subsubsection{Equilibrium}

We proceed with equilibrium analysis under complete segmentation for the domestic securities market $(h \in \mathcal{D}$ and $m=d)$ and for the foreign market $(h \in \mathcal{F}$ and $m=f)$. Equilibrium prices in each market are determined by the demand from the investors in risky assets. Define the set of investors who pay fixed participation cost and decide to participate in their respective market,

$$
\begin{aligned}
& \mathcal{D}_{S}^{p} \equiv\left\{h \in \mathcal{D}: \frac{1}{2 a}\left(\overline{\mathbf{z}}_{d}-R_{d} \mathbf{p}_{S, d}-a \boldsymbol{\sigma}_{e, d}^{h}\right)^{\prime} \Sigma_{d}^{-1}\left(\overline{\mathbf{z}}_{d}-R_{d} \mathbf{p}_{S, d}-a \boldsymbol{\sigma}_{e, d}^{h}\right)>R_{d} k_{d}\right\}, \\
& \mathcal{F}_{S}^{p} \equiv\left\{h \in \mathcal{F}: \frac{1}{2 a}\left(\overline{\mathbf{z}}_{f}-R_{f} \mathbf{p}_{S, f}-a \boldsymbol{\sigma}_{e, f}^{h}\right)^{\prime} \Sigma_{f}^{-1}\left(\overline{\mathbf{z}}_{f}-R_{f} \mathbf{p}_{S, f}-a \boldsymbol{\sigma}_{e, f}^{h}\right)>R_{f} k_{f}\right\} .
\end{aligned}
$$

That is, $\mathcal{D}_{S}^{p} \subset \mathcal{D}$ is the subset of domestic investors who participate in the domestic securities market. Similarly, $\mathcal{F}_{S}^{p} \subset \mathcal{F}$ is the subset of foreign investors who participate in the foreign securities market. For brevity, we use $\mathcal{M}_{S}$ to denote the set of market participants in either domestic $\left(\mathcal{M}_{S}=\mathcal{D}_{S}^{p}\right)$ or a foreign $\left(\mathcal{M}_{S}=\mathcal{F}_{S}^{p}\right)$ market.

The demand for risky assets comes from market participants in the domestic or foreign market. Assets are in zero net supply in both markets, so the market clearing price $\mathbf{p}_{S, m}$ is determined from

$$
\mathbf{0}=\int_{\mathcal{M}_{S}} \boldsymbol{\theta}_{S, m}^{h p} d \mathbb{P}^{m}(h)=\int_{\mathcal{M}_{S}} \frac{1}{a} \Sigma_{m}^{-1}\left(\overline{\mathbf{z}}_{m}-R_{m} \mathbf{p}_{S, m}-a \boldsymbol{\sigma}_{e, m}^{h}\right) d \mathbb{P}^{m}(h) .
$$

\footnotetext{
${ }^{8}$ The quantity on the right-hand-side also may change if investors need to bear additional fixed costs when investing abroad.
} 
Define the average random terminal endowment of market participants as

$$
\widetilde{e}^{\mathcal{M}_{S}}=\int_{\mathcal{M}_{S}} \widetilde{e}^{h} d \mathbb{P}^{m}(h)
$$

The following result obtains.

Theorem 2 (Equilibrium Asset Prices) In equilibrium under complete market segmentation, the price of risky asset $i$ from the market $m$ is given by

$$
p_{S, m}(i)=\frac{1}{R_{m}}\left[\bar{z}(i)-\frac{a}{\mathbb{P}^{m}\left(\mathcal{M}_{S}\right)} \operatorname{Cov}\left(\widetilde{z}(i), \widetilde{e}^{\mathcal{M}_{S}}\right)\right] .
$$

Proof. Multiply both sides of

$$
\mathbf{0}=\int_{\mathcal{M}_{S}} \boldsymbol{\theta}_{S, m}^{h p} d \mathbb{P}^{m}(h)
$$

by $a \Sigma_{m}$ and use the definition of $\widetilde{e}^{\mathcal{M}_{S}}$.

When all agents participate in the risky asset market, $\mathbb{P}\left(\mathcal{M}_{S}\right)=1$, and the pricing result becomes the standard Consumption CAPM result (assets are priced by their covariance with the aggregate endowment). Assets that provide a good hedge are more valuable and command a higher price. In the model with endogenous participation the quality of hedging provided by an asset is measured by a weighted average covariance term that takes into account income characteristics of the set of participating agents. This term is

$$
\operatorname{Cov}\left(\widetilde{z}(i), \widetilde{e}^{\mathcal{M}_{S}}\right)=\operatorname{Cov}\left(\widetilde{z}(i), \int_{\mathcal{M}_{S}} \widetilde{e}^{h} d \mathbb{P}^{m}(h)\right)=\int_{\mathcal{M}_{S}} \operatorname{Cov}\left(\widetilde{z}(i), \widetilde{e}^{h}\right) d \mathbb{P}^{m}(h) .
$$

\subsection{Partial Liberalization}

Partial liberalization takes place when a country opens its stock market to foreign investors, but barriers remain that preclude its residents from investing abroad. In our setting, partial liberalization means that foreign investors can hold foreign and domestic risky assets and that domestic investors can hold only domestic risky assets. Foreign investors also hold the foreign risk-free asset but not the domestic bond. Domestic investors hold the domestic bond and do not have access to the foreign risk-free security. We interpret the bond available to domestic investors not as an asset that has no risk, but as a storage technology. In many countries such storage technology amounts to holding cash in US dollars or in Euro. Both foreign and domestic investors first make 
a participation decision. An investor may decide to pay the fixed cost, $k_{d}$ for a domestic investor or $k_{f}$ for a foreign investor, and invest in risky assets within his opportunity set. Alternatively, an investor may decide to invest in a risk-free bond only. The decision to participate is endogenous. Subscript ${ }_{P}$ denotes the values under partial liberalization.

\subsubsection{Domestic Investors}

A domestic investor faces the same opportunity set as in the case of complete segmentation, defined by $\overline{\mathbf{z}}_{d}, \Sigma_{d}, \boldsymbol{\sigma}_{e, d}^{h}$, and $R_{d}$, except prices of domestic risky assets are different under partial liberalization and complete segmentation, $\mathbf{p}_{P, d} \neq \mathbf{p}_{S, d}$. Partial liberalization affects domestic investors through changes in the prices of domestic risky assets. Domestic participant solves a utility maximization problem identical to the case of strong segmentation, described in detail in the Appendix. All analytical expressions are the same as in the complete segmentation case, with the new vector of risky asset prices, $\mathbf{p}_{P, d}$, substituted in place of the old prices, $\mathbf{p}_{S, d}$. The participant's indirect utility function is

$$
\begin{aligned}
J_{P, d}^{p}\left[W_{0}^{h}\right]= & -\left(1+R_{d}\right) \delta \\
& \exp \left\{-\frac{a}{1+R_{d}}\left[\bar{e}^{h}+R_{d}\left(W_{0}^{h}-k_{d}\right)+\frac{R_{d} \ln \delta R_{d}}{a}-\frac{a \sigma_{e^{h}}^{2}}{2}+\frac{S_{P, d}^{2}(h)}{2 a}\right]\right\}
\end{aligned}
$$

where $S_{P, d}^{2}(h) \equiv\left(\overline{\mathbf{z}}_{d}-R_{d} \cdot \mathbf{p}_{P, d}-a \boldsymbol{\sigma}_{e, d}^{h}\right)^{\prime} \Sigma_{d}^{-1}\left(\overline{\mathbf{z}}_{d}-R_{d} \cdot \mathbf{p}_{P, d}-a \boldsymbol{\sigma}_{e, d}^{h}\right)$

Optimization problem of domestic non-participant is identical to the case of strong segmentation. The non-participant's indirect utility function is

$$
J_{P, d}^{n}\left[W_{0}^{h}\right]=-\delta\left(1+R_{d}\right) \exp \left[-\frac{a}{1+R_{d}}\left[\bar{e}^{h}+R_{d} W_{0}^{h}+\frac{R_{d} \ln \delta R_{d}}{a}-\frac{a}{2} \sigma_{e_{d}^{h}}^{2}\right]\right] .
$$

The participation criterion is obtained by substituting risky asset prices of $\mathbf{p}_{P, d}$ into (1). A domestic investor will pay the participation fee $k_{d}$ and invest in domestic risky assets when

$$
\frac{1}{2 a}\left(\overline{\mathbf{z}}_{d}-R_{d} \mathbf{p}_{P, d}-a \boldsymbol{\sigma}_{e, d}^{h}\right)^{\prime} \Sigma_{d}^{-1}\left(\overline{\mathbf{z}}_{d}-R_{d} \mathbf{p}_{P, d}-a \boldsymbol{\sigma}_{e, d}^{h}\right)>R_{d} k_{d}
$$

Generally, domestic investors can be classified into four types. Type A investors participate in the domestic risky asset market before and after partial liberalization. Type B investors never participate in the risky asset market. Type $\mathbf{C}$ agents participate if and only if partial liberalization 
takes place and Type $\mathbf{D}$ investors participate if and only if partial liberalization does not takes place. For types A and B financial liberalization does not affect participation. For types C and D the opposite is true, their participation decision is affected by the liberalization decision.

\subsubsection{Foreign Investors}

Partial liberalization changes risky investment opportunities available to a foreign investor. The vector of expected payoffs $\overline{\mathbf{z}}$, the variance-covariance matrix of asset payoffs $\Sigma$, and the vector of covariances between the endowment payoff and all available assets are now given by,

$$
\overline{\mathbf{z}} \equiv\left(\begin{array}{c}
\overline{\mathbf{z}}_{d} \\
\overline{\mathbf{z}}_{f}
\end{array}\right) ; \quad \Sigma \equiv\left(\begin{array}{cc}
\Sigma_{d} & \Sigma_{d, f} \\
\Sigma_{d, f}^{\prime} & \Sigma_{f}
\end{array}\right) ; \quad \boldsymbol{\sigma}_{e}^{h} \equiv\left(\begin{array}{c}
\boldsymbol{\sigma}_{e, d}^{h} \\
\boldsymbol{\sigma}_{e, f}^{h}
\end{array}\right) .
$$

Foreign investor who participates in the risky asset market solves

$$
\begin{aligned}
J_{P, f}^{p}\left[W_{0}^{h}\right] & =\max _{c_{P, f, 0}^{h}, \boldsymbol{\theta}_{P, f}^{h}, \theta_{P, f, 0}^{h}}\left\{-e^{-a c_{P, f, 0}^{h}}-\delta \mathbb{E} e^{-a \widetilde{c}_{P, f, 1}^{h}}\right\}, \\
W_{0}^{h} & =c_{P, f, 0}^{h}+\mathbf{p}_{P}^{\prime} \cdot \boldsymbol{\theta}_{P, f}^{h}+k_{f}+\theta_{P, f, 0}^{h} / R_{f} .
\end{aligned}
$$

with respect to time 0 consumption $c_{P, f, 0}^{h}$; time 0 post-trade holdings of risky assets $\boldsymbol{\theta}_{P, f}^{h}$; and time 0 investment in the bond, $\theta_{P, f, 0}^{h}$. The dimension of vector $\boldsymbol{\theta}_{P, f}^{h}$ equals the number of both domestic and foreign assets. The vector of prices includes prices of domestic and foreign risky assets, $\mathbf{p}_{P}=\left(\mathbf{p}_{P, d}^{\prime}, \mathbf{p}_{P, f}^{\prime}\right)^{\prime}$. Optimal consumption-portfolio policy is given in the Appendix. Foreign participant's indirect utility function is,

$$
\begin{aligned}
J_{P, f}^{p}\left[W_{0}^{h}\right]= & -\left(1+R_{f}\right) \delta \cdot \\
& \exp \left\{-\frac{a}{1+R_{f}}\left[\bar{e}^{h}+R_{f}\left(W_{0}^{h}-k_{f}\right)+\frac{R_{f} \ln \delta R_{f}}{a}-\frac{a \sigma_{e^{h}}^{2}}{2}+\frac{S_{P, f}^{2}(h)}{2 a}\right]\right\},
\end{aligned}
$$

where $S_{P, f}^{2}(h) \equiv\left(\overline{\mathbf{z}}-R_{f} \cdot \mathbf{p}_{P}-a \boldsymbol{\sigma}_{e}^{h}\right)^{\prime} \Sigma^{-1}\left(\overline{\mathbf{z}}-R_{f} \cdot \mathbf{p}_{P}-a \boldsymbol{\sigma}_{e}^{h}\right)$.

The optimization problem and the indirect utility function of a foreign non-participant, are identical to the case of strong segmentation. The participation criterion is obtained by substituting $\mathbf{p}_{P}, \overline{\mathbf{z}}, \Sigma$, and $\boldsymbol{\sigma}_{e}^{h}$ into (1). A foreign investor will pay the participation fee $k_{f}$ and invest in foreign and domestic risky assets when

$$
\frac{1}{2 a}\left(\overline{\mathbf{z}}-R_{f} \mathbf{p}_{P}-a \boldsymbol{\sigma}_{e}^{h}\right)^{\prime} \Sigma^{-1}\left(\overline{\mathbf{z}}-R_{f} \mathbf{p}_{P}-a \boldsymbol{\sigma}_{e}^{h}\right)>R_{f} k_{f}
$$


Generally, there are four types of foreign investors. These types are similar to the four types of domestic investors. Type A investors participate in the risky asset market before and after partial liberalization. Type B investors never participate in the risky asset market. Type $\mathbf{C}$ agents participate if and only if partial liberalization takes place and Type $\mathbf{D}$ investors participate if and only if partial liberalization does not takes place.

\subsubsection{Equilibrium Under Partial Liberalization}

In equilibrium under partial liberalization, participation among domestic and foreign investors, and prices of risky assets in both foreign and domestic markets are jointly determined. Asset prices of foreign securities are determined by the demand from participating foreign investors. Asset prices of domestic securities are determined by the demand from foreign and domestic participants. The sets of participants are in turn determined by asset prices. Define the set of investors who pay fixed participation cost and participate when domestic market is partially liberalized,

$$
\begin{aligned}
\mathcal{D}_{P}^{p} & \equiv\left\{h \in \mathcal{D}: \frac{1}{2 a}\left(\overline{\mathbf{z}}_{d}-R_{d} \mathbf{p}_{P, d}-a \boldsymbol{\sigma}_{e, d}^{h}\right)^{\prime} \Sigma_{d}^{-1}\left(\overline{\mathbf{z}}_{d}-R_{d} \mathbf{p}_{P, d}-a \boldsymbol{\sigma}_{e, d}^{h}\right)>R_{d} k_{d}\right\}, \\
\mathcal{F}_{P}^{p} & \equiv\left\{h \in \mathcal{F}: \frac{1}{2 a}\left(\overline{\mathbf{z}}-R_{f} \mathbf{p}_{P}-a \boldsymbol{\sigma}_{e}^{h}\right)^{\prime} \Sigma^{-1}\left(\overline{\mathbf{z}}-R_{f} \mathbf{p}_{P}-a \boldsymbol{\sigma}_{e}^{h}\right)>R_{f} k_{f}\right\}, \\
\text { where } \mathbf{p}_{P} & \equiv\left(\mathbf{p}_{P, d}^{\prime}, \mathbf{p}_{P, f}^{\prime}\right)^{\prime} .
\end{aligned}
$$

That is, $\mathcal{D}_{P}^{p} \subset \mathcal{D}$ is the subset of domestic investors and $\mathcal{F}_{P}^{p} \subset \mathcal{F}$ is the subset of foreign investors who participate in the partially liberalized securities market. As before, $\mathcal{M}_{P, m}$ denotes the set of market participants in market $m(m=d$ or $m=f)$. The sets $\mathcal{D}_{P}^{p}$ and $\mathcal{F}_{P}^{p}$ and asset prices, $\mathbf{p}_{P, d}$ and $\mathbf{p}_{P, f}$ are jointly determined in equilibrium. Define the average terminal endowment of market participants from each market as

$$
\widetilde{e}^{\mathcal{D}_{P}^{p}}=\int_{\mathcal{D}_{P}^{p}} \widetilde{e}^{h} d \mathbb{P}^{d}(h), \quad \widetilde{e}^{\mathcal{F}_{P}^{p}}=\int_{\mathcal{F}_{P}^{p}} \widetilde{e}^{h} d \mathbb{P}^{f}(h) .
$$

The demand for foreign stocks comes from foreign investors only. This is exactly as in the case of complete segmentation. Hence, the price of a risky asset $i$ from the foreign market is given by,

$$
p_{P, f}(i)=\frac{1}{R_{f}}\left[\bar{z}(i)-\frac{a}{\mathbb{P}^{f}\left(\mathcal{F}_{P}^{p}\right)} \operatorname{Cov}\left(\widetilde{z}(i), \widetilde{e}^{\mathcal{F}_{P}^{p}}\right)\right] .
$$


The demand for domestic stocks comes from both foreign and domestic participants. Assets are in zero net supply in both markets, so the vector of market clearing prices $\mathbf{p}_{P, d}$ is determined from

$$
\begin{aligned}
\mathbf{0}= & \int_{\mathcal{D}_{P}^{p}} \boldsymbol{\theta}_{P, d}^{h p} d \mathbb{P}^{d}(h)+\int_{\mathcal{F}_{P}^{p}} \boldsymbol{\theta}_{P, f}^{h p} d \mathbb{P}^{f}(h) \\
= & \int_{\mathcal{D}_{P}^{p}} \frac{1}{a} \Sigma_{d}^{-1}\left(\overline{\mathbf{z}}_{d}-R_{d} \cdot \mathbf{p}_{P, d}-a \boldsymbol{\sigma}_{e, d}^{h}\right) d \mathbb{P}^{d}(h) \\
& +\int_{\mathcal{F}_{P}^{p}} \frac{1}{a} \Sigma^{-1}\left(\overline{\mathbf{z}}-R_{f} \cdot\left(\mathbf{p}_{P, d}^{\prime}, \mathbf{p}_{P, f}^{\prime}\right)^{\prime}-a \boldsymbol{\sigma}_{e}^{h}\right) d \mathbb{P}^{f}(h) .
\end{aligned}
$$

As previously shown, under complete segmentation domestic assets are priced by their covariance with the endowment of domestic participants only. When barriers to foreign investment are removed, domestic risky assets are priced by covariance between the asset payoff and the endowment of both foreign and domestic market participants. Comparing the expressions for domestic asset price under complete segmentation and partial liberalization, we conclude that partial liberalization generally causes the price of domestic assets to change, because it changes the covariance structure between assets and endowments for the domestic securities. In a recent study using firmlevel data from 18 emerging markets, Patro and Wald (2004) report evidence consistent with this model. They find that emerging market firms have increased exposure to the world market and decreased exposure to the home market following liberalization. ${ }^{9}$ Our results in the general case show that removal of investment barriers affects prices and, therefore, the pattern of participation among domestic and foreign agents. Changing prices and changing participation leads to welfare effect. It is impossible to characterize this welfare effect without further describing the risks of this economy. Even though some domestic agents remain non-participants they may gain in utility. In the next section we show with a simple factor model and a uniform distribution of factors that there can be a welfare loss for both participants and non-participants and an aggregate loss for the economy.

\footnotetext{
${ }^{9}$ This is also consistent with findings in Bekaert and Harvey $(1995,1997)$ who show that the effect of world factors on domestic stock market is a function of market integration and the influence of global factors could increase after foreign investment liberalizations.
} 


\section{$3 \quad$ A Single Factor Model}

Assume that endowment and asset payoffs are described by a linear factor model,

$$
\begin{array}{ll}
\widetilde{e}^{h}=\bar{e}^{h}+b_{d}^{h} \widetilde{f}_{d}+\widetilde{\varepsilon}_{m}^{h}, \quad h \in \mathcal{D} \\
\widetilde{e}^{h}=\bar{e}^{h}+b_{f}^{h} \widetilde{f}_{f}+\widetilde{\varepsilon}_{m}^{h}, \quad h \in \mathcal{F} \\
\widetilde{z}_{d}=\bar{z}_{d}+\beta_{d} \widetilde{f}_{d}+\widetilde{\varepsilon}_{d}, & \\
\widetilde{z}_{f}=\bar{z}_{f}+\beta_{f} \widetilde{f}_{f}+\widetilde{\varepsilon}_{f} . &
\end{array}
$$

There are two risk factors, domestic, $\widetilde{f}_{d}$, and foreign, $\widetilde{f}_{f}$. Random variables $\widetilde{\varepsilon}^{h}, \widetilde{\varepsilon}_{d}$, and $\widetilde{\varepsilon}_{f}$ represent residual (idiosyncratic) risks. All random variables are independent and are Normally distributed. A domestic agent $(h \in \mathcal{D})$ has an agent-specific loading $b_{d}^{h}$ on the domestic risk factor. A foreign agent $(h \in \mathcal{F})$ has an agent-specific loading $b_{f}^{h}$ on the foreign risk factor. There is one domestic risky asset and one foreign risky asset (each representing the market portfolio of the corresponding market). The payoff on domestic asset depends on the domestic risk factor. The payoff on the foreign asset depends on the foreign factor. It is assumed that $\bar{e}^{h}=b_{d}^{h}, \forall h \in \mathcal{D}$ and $\bar{e}^{h}=b_{f}^{h}, \forall h \in \mathcal{F}$. The usual assumptions about the factors and the error terms are made $(m=d, f)$ :

$$
\begin{aligned}
\mathbb{E}\left[\widetilde{\varepsilon}^{h}\right] & =\mathbb{E}\left[\widetilde{\varepsilon}_{m}\right]=\mathbb{E}\left[\widetilde{f}_{m}\right]=0, \\
\mathbb{E}\left[\widetilde{\varepsilon}^{h} \widetilde{\varepsilon}_{d}\right] & =\mathbb{E}\left[\widetilde{\varepsilon}^{h} \widetilde{\varepsilon}_{f}\right]=\mathbb{E}\left[\widetilde{\varepsilon}_{d} \widetilde{\varepsilon}_{f}\right]=\mathbb{E}\left[\widetilde{\varepsilon}^{h} \widetilde{f}_{m}\right]=\mathbb{E}\left[\widetilde{\varepsilon}_{m} \widetilde{f}_{m}\right]=\mathbb{E}\left[\widetilde{f}_{d} \widetilde{f}_{f}\right]=0, \\
\mathbb{E}\left[\left(\widetilde{\varepsilon}^{h}\right)^{2}\right] & =\sigma_{\varepsilon_{m}^{h}}^{2}, \quad \mathbb{E}\left[\widetilde{\varepsilon}_{d}^{2}\right]=\sigma_{\varepsilon_{d}}^{2}, \quad \mathbb{E}\left[\widetilde{\varepsilon}_{f}^{2}\right]=\sigma_{\varepsilon_{f}}^{2}, \\
\mathbb{E}\left[\widetilde{f}_{d}^{2}\right] & =\mathbb{E}\left[\widetilde{f}_{f}^{2}\right]=1 .
\end{aligned}
$$

All error terms and factors are mutually independent. Total variance of asset $m$ is $\operatorname{Var}\left[\widetilde{z}_{m}\right]=$ $\beta_{m}^{2}+\sigma_{\varepsilon_{m}}^{2}=\sigma_{z_{m}}^{2}$.

It is also necessary to specify the distributions of factor loadings in the population of domestic and foreign investors. It is assumed that the endowment factor loadings are independent in the population of foreign investors from the population of domestic investors, with probability density functions $P D F^{f}\left(b_{f}^{h}\right)$ and $P D F^{d}\left(b_{d}^{h}\right)$. 


\subsection{Complete Segmentation}

As discussed in the general case, in equilibrium the set of market participants and the price of risky assets are jointly determined for both domestic and foreign markets. Under complete market segmentation, equilibrium in each market is described by the following system of equations, ${ }^{10}$

$$
\begin{aligned}
p_{S, m} & =\frac{1}{R_{m}}\left[\bar{z}_{m}-\frac{a}{\mathbb{P}^{m}\left(\mathcal{M}_{S}\right)} \operatorname{Cov}\left(\widetilde{z}_{m}, \widetilde{e}^{\mathcal{M}_{S}}\right)\right] \\
\mathcal{M}_{S} & \equiv\left\{h: S_{S, m}^{2}(h) \equiv a^{2} \frac{\beta_{m}^{2}}{\beta_{m}^{2}+\sigma_{\varepsilon_{m}}^{2}}\left[b_{m}^{\mathcal{M}_{S}}-b_{m}^{h}\right]^{2}>2 a R_{m} k_{m}\right\}, \\
\operatorname{Cov}\left(\widetilde{z}_{m}, \widetilde{e}^{\mathcal{M}_{S}}\right) & =\beta_{m} \int_{\mathcal{M}_{S}} b_{m}^{h} d \mathbb{P}^{m}(h), \\
\widetilde{e}^{\mathcal{M}_{S}} & \equiv \int_{\mathcal{M}_{S}} \widetilde{e}^{h} d \mathbb{P}^{m}(h), \quad b_{m}^{\mathcal{M}_{S}} \equiv \frac{1}{\mathbb{P}^{m}\left(\mathcal{M}_{S}\right)} \int_{\mathcal{M}_{S}} b_{m}^{h} d \mathbb{P}^{m}(h) .
\end{aligned}
$$

The last equation defines $b_{m}^{\mathcal{M}}$, the average loading on the market risk factor among the participants in the risky asset market $m$. Participation criterion indicates that the set of market participants consists of agents whose factor loadings $b_{m}^{h}$ are sufficiently far away from the market average loading $b_{m}^{\mathcal{M}}$. For these agents the benefits measured by $S_{S, m}^{2}(h)$ are sufficiently high to justify the entrance fee.

The ratio $\alpha_{m}^{2} \equiv \beta_{m}^{2} /\left(\beta_{m}^{2}+\sigma_{\varepsilon_{m}}^{2}\right)$ is the ratio of variance of the asset payoff from the factor risk to the total asset payoff variance. It is the measure of quality of hedging that the risky asset provides. Agents want to hedge the factor risk. If asset idiosyncratic variance is very low, $\sigma_{\varepsilon_{m}}^{2} \approx 0$, then almost all of the asset variance comes from the factor risk, $\alpha_{m}^{2} \approx 1$ and the asset provides a good hedge. Conversely, if idiosyncratic variance dominates, $\sigma_{\varepsilon_{m}}^{2}>>\beta_{m}^{2}$, then the asset does not provide a good hedge, and $\alpha_{m}^{2}$ is low. In this case, holding all else equal, the left-hand-side of the participation criterion is relatively small, affecting participation decision.

Factor loadings of participating investors are sufficiently far away from the market average loading. This is evident since the solution set for inequality $a(b-x)^{2}>c$ is $x \in(-\infty, b-\sqrt{c / a}) \cup$ $(b+\sqrt{c / a},+\infty)$. Define $K_{m} \equiv 2 a R_{m} k_{m} /\left(a^{2} \alpha_{m}^{2}\right)$. Then

$$
\mathbb{P}^{m}\left(\mathcal{M}_{S}\right)=\int_{-\infty}^{b_{m}^{\mathcal{M}_{S}}-\sqrt{K_{m}}} P D F^{m}\left(b_{m}^{h}\right) d b_{m}^{h}+\int_{b_{m}^{\mathcal{M}_{S}}+\sqrt{K_{m}}}^{+\infty} P D F^{m}\left(b_{m}^{h}\right) d b_{m}^{h}
$$

\footnotetext{
${ }^{10}$ See Appendix for details.
} 
and $b_{m}^{\mathcal{M}_{S}}$ is the solution to

$$
\frac{1}{\mathbb{P}^{m}\left(\mathcal{M}_{S}\right)}\left[\int_{-\infty}^{b_{m}^{\mathcal{M}_{S}}-\sqrt{K_{m}}} b_{m}^{h} P D F\left(b_{m}^{h}\right) d b_{m}^{h}+\int_{b_{m}^{\mathcal{M}_{S}}+\sqrt{K_{m}}}^{+\infty} b_{m}^{h} P D F^{m}\left(b_{m}^{h}\right) d b_{m}^{h}\right]=b_{m}^{\mathcal{M}_{S}} .
$$

The set of participating agents is then $\mathcal{M}_{S}=\left(-\infty, b_{m}^{\mathcal{M}_{S}}-\sqrt{K_{m}}\right) \cup\left(b_{m}^{\mathcal{M}_{S}}+\sqrt{K_{m}},+\infty\right)$.

The analysis so far did not rely on any assumptions about the distribution of factor loadings in the population. Assume that the factor loading has a uniform distribution, $b_{m}^{h} \sim$ Uniform $\left(b_{m}^{\min }, b_{m}^{\max }\right)$, $P D F^{m}\left(b_{m}^{h}\right)=1 /\left(b_{m}^{\max }-b_{m}^{\min }\right) \cdot{ }^{11}$ Then, by direct computation

$$
\mathbb{P}^{m}\left(\mathcal{M}_{S}\right)=\frac{b_{m}^{\max }-b_{m}^{\min }-2 \sqrt{K_{m}}}{b_{m}^{\max }-b_{m}^{\min }} \text { and } b_{m}^{\mathcal{M}_{S}}=\frac{1}{2}\left(b_{m}^{\max }+b_{m}^{\min }\right) .
$$

The center of mass in this economy, $b_{m}^{\mathcal{M}_{S}}$, is a constant.

The relative price of the risky asset is

$$
p_{S, m} / R_{m}^{-1}=\bar{z}_{m}-a \cdot \beta_{m} \cdot b_{m}^{\mathcal{M}_{S}}=\bar{z}_{m}-a \cdot \beta_{m} \cdot \frac{1}{2}\left(b_{m}^{\max }+b_{m}^{\min }\right) .
$$

The assumption that factor loadings have uniform distribution is made for tractability. It allows us to focus on a simple symmetric case, without forcing a more restrictive distribution of factor risks on the economy. The assumption points to the role that the distribution of systematic endowment risk among agents has on the risky asset price. It is also important for the effect that a changing investor participation may have on the price of a risky asset. For example, if the participation fee is lowered, more agents will participate, but the average factor loading among participants will stay constant and the relative price of the risky asset will not change. Thus, even though more agents will enter the market for the risky asset, the price of the asset will not change. This happens because there is a symmetry among the new entrants. There will be as many new investors buying the asset as there will be new investors selling it short. An increase in demand will be matched to the increase in the supply and the price will remain unchanged.

\footnotetext{
${ }^{11}$ The assumption of uniformly distributed factor loadings is not necessary to obtain our main results. This assumption is made for analytical tractability when aggregating across agents. Our results obtain with other distributions of agents. The assumption of uniform distribution has one added benefit. It is a neutral assumption about the distribution of different agent types. By making this assumption we do not make statements about the prevalence of any type of agent in the domestic and foreign economies. All agent types have equal weight and we do not introduce any biases.
} 
Figure 1 illustrates the effect of "asset quality" $\left(\alpha_{d}^{2}\right)$ on participation decision. The figure shows the boundaries of the set of domestic participating agents in the case of complete segmentation as a function of domestic participation cost, $k_{d}$. Participant set is the set of values outside of the boundary line. The relationship between the boundaries and the participation cost is shown for two values of domestic idiosyncratic variance, $\sigma_{\varepsilon_{d}}^{2}$, "low" and "high." When the idiosyncratic variance is low, the quality of the asset is high, and the set of participating agents (the area outside of the boundary) is larger. When the idiosyncratic variance is high the quality of the asset is lower from the point of view of domestic agents, and consequently, a smaller set of agents finds it beneficial to participate in the risky asset market.

\subsection{Partial Liberalization}

Four quantities are jointly determined in equilibrium: the sets of domestic $\left(\mathcal{D}_{P}^{p}\right)$ and foreign $\left(\mathcal{F}_{P}^{p}\right)$ participating agents, and the prices of risky assets, $p_{P, d}$ and $p_{P, f}$.

A domestic investor $h \in \mathcal{D}$ participates if and only if $S_{P}^{2}(h)>2 a R_{d} k_{d}$. For participating domestic agents factor loadings $b_{d}^{h}$ satisfy:

$$
\left(\bar{z}_{d}-R_{d} p_{P, d}-a b_{d}^{h} \beta_{d}\right)^{2}>2 a R_{d} k_{d} \operatorname{Var}\left[\widetilde{z}_{d}\right], \quad h \in \mathcal{D}
$$

The boundaries of the set of participating agents, $\mathcal{D}_{P}^{p}$, are given by the solution to the quadratic equation that correspond to the above inequality,

$$
\mathcal{D}_{P}^{p}=\left(-\infty, \frac{\bar{z}_{d}-R_{d} p_{P, d}}{a \beta_{d}}-\sqrt{K_{d}}\right) \cup\left(\frac{\bar{z}_{d}-R_{d} p_{P, d}}{a \beta_{d}}+\sqrt{K_{d}},+\infty\right)
$$

For a uniform distribution $b_{d}^{h} \sim \operatorname{Uniform}\left(b_{d}^{\min }, b_{d}^{\max }\right)$, it is shown in the Appendix that

$$
\begin{aligned}
\mathcal{D}_{P}^{p} & =\left(-\infty, \frac{b_{d}^{\mathcal{D}_{S, d}}}{1+\mathbb{P}^{f}\left(\mathcal{F}_{P}^{p}\right)}-\sqrt{K_{d}}\right) \cup\left(\frac{b_{d}^{\mathcal{D}_{S, d}}}{1+\mathbb{P}^{f}\left(\mathcal{F}_{P}^{p}\right)}+\sqrt{K_{d}},+\infty\right) \\
\mathbb{P}^{d}\left(\mathcal{D}_{P}^{p}\right) & =1-\frac{2 \sqrt{2 a R_{d} k_{d} \operatorname{Var}\left[\widetilde{z}_{d}\right]}}{\beta_{d} a\left(b_{d}^{\text {max }}-b_{d}^{\text {min }}\right)}=\mathbb{P}^{d}\left(\mathcal{D}_{S}^{p}\right) .
\end{aligned}
$$

As previously defined, $b_{d}^{\mathcal{D}_{S}}=\frac{1}{2}\left(b_{m}^{\max }+b_{m}^{\min }\right)$ is the center of mass in the domestic economy under complete segmentation.

A foreign investor participates if and only if $S_{f}^{2}(h)>2 a R_{f} k_{f}$. For a foreign investor the generalized Sharpe ratio is given by

$$
S_{P}^{2}(h)=\frac{1}{\operatorname{Var}\left[\widetilde{z}_{d}\right]}\left(\bar{z}_{d}-R_{f} p_{P, d}\right)^{2}+\frac{1}{\operatorname{Var}\left[\widetilde{z}_{f}\right]}\left(\bar{z}_{f}-R_{f} p_{P, f}-a b_{f}^{h} \beta_{f}\right)^{2} .
$$


The set of foreign participants is, therefore, determined by a quadratic equation in $b_{f}^{h}$, which enters the expression above through the terms that contain $\widetilde{e}^{h}$. Solving the quadratic equation, we obtain boundaries of the participation set,

$$
\begin{aligned}
b_{f}^{h *} & =\frac{\left(\bar{z}_{f}-R_{f} p_{P, f}\right)}{a \beta_{f}}-\frac{\sqrt{C}}{a \beta_{f} \sqrt{\operatorname{Var}\left[\widetilde{z}_{d}\right]}} \\
b_{f}^{h * *} & =\frac{\left(\bar{z}_{f}-R_{f} p_{P, f}\right)}{a \beta_{f}}+\frac{\sqrt{C}}{a \beta_{f} \sqrt{\operatorname{Var}\left[\widetilde{z}_{d}\right]}} \\
\sqrt{C} & \equiv \sqrt{\operatorname{Var}\left[\widetilde{z}_{f}\right]} \sqrt{2 a R_{f} k_{f} \operatorname{Var}\left[\widetilde{z}_{d}\right]-\left(\bar{z}_{d}-R_{f} p_{P, d}\right)^{2}}
\end{aligned}
$$

Since the rays of the parabola are pointing upward, the set of participating foreign agents is

$$
\mathcal{F}_{P}^{p}=\left(-\infty, b_{f}^{h *}\right) \cup\left(b_{f}^{h * *},+\infty\right) .
$$

The price of the foreign asset is the same as under complete segmentation, and is given by

$$
p_{P, f}=p_{S f}=\frac{1}{R_{f}}\left[\bar{z}_{f}-a \beta_{f} \frac{b^{\max }+b^{\min }}{2}\right] .
$$

The price of domestic asset is, ${ }^{12}$

$$
\bar{z}_{d}-p_{P, d} R_{d}=a \beta_{d} \frac{b_{d}^{\min }+b_{d}^{\max }}{2\left[1+\mathbb{P}^{f}\left(\mathcal{F}_{P}^{p}\right)\right]},
$$

where

$$
\mathbb{P}^{f}\left(\mathcal{F}_{P}^{p}\right)=1-\frac{2 \sqrt{C}}{a \beta_{f} \sqrt{\operatorname{Var}\left[\widetilde{z}_{d}\right]}\left(b_{f}^{\max }-b_{f}^{\min }\right)} .
$$

To see the effect of partial liberalization on domestic asset price, compare domestic risk premium under partial liberalization and complete segmentation.

Theorem 3 Consider a CARA-Normal economy with endogenous participation and with heterogeneous agents. Let asset returns and endowment payoffs be generated according to a linear factor structure (2)-(5). Under partial liberalization, the absolute value of the risk premium falls in the domestic market.

\footnotetext{
${ }^{12}$ We make a standard assumption in the literature: $R_{f}=R_{d}$ (the assumption of equal worldwide interest rates is made for example by Errunza and Losq (1989)).
} 
Proof. The expressions for the risk premium under partial liberalization and under complete segmentation, respectively, are:

$$
\bar{z}_{d}-p_{P, d} R_{d}=a \beta_{d} \frac{b_{d}^{\min }+b_{d}^{\max }}{2\left[1+\mathbb{P}^{f}\left(\mathcal{F}_{P}^{p}\right)\right]}, \text { and } \bar{z}_{d}-p_{S, d} R_{d}=a \beta_{d} \frac{b_{d}^{\max }+b_{d}^{\min }}{2} .
$$

Since $0<\mathbb{P}^{f}\left(\mathcal{F}_{P}^{p}\right)<1$, the absolute value of the risk premium falls in the domestic market.

The result that the absolute value of the risk premium falls with liberalization is a standard result in international CAPM. We show that the result holds in a general equilibrium with incomplete markets (GEI) setting.

Corollary 4 Suppose domestic asset has a positive beta, $\beta_{d}>0$, and domestic economy has a positive center of mass, $b_{d}^{\mathcal{D}_{S}}>0$. This is the case that corresponds to a classical international CAPM (a positive expected return on a market portfolio). Then, domestic risk premium is positive under complete segmentation and falls under partial liberalization. The price of domestic risky asset rises.

Proof. Domestic risk premium under complete segmentation is positive because, by assumption $\beta_{d}>0$ and $b_{d}^{\mathcal{D}_{S}}=\frac{1}{2}\left(b_{m}^{\max }+b_{m}^{\min }\right)>0$.

Figure 2 illustrates the effect of partial liberalization on the set of domestic participants. The figure shows participation set under complete segmentation, with the center of mass of the economy $b_{d}^{\mathcal{D}_{S}}$. Suppose the initial center of mass is positive, $b_{d}^{\mathcal{D}_{S}}>0$ (the economy has a positive exposure to the risk factor). This case is represented on the bottom diagram of the figure. After partial liberalization foreign agents enter the economy and the center of mass shifts to the left,

$$
b_{d}^{\mathcal{D}_{P}}=b_{d}^{\mathcal{D}_{S}} \cdot \frac{1}{1+\mathbb{P}^{f}\left(\mathcal{F}_{P}^{p}\right)}<b_{d}^{\mathcal{D}_{S}}
$$

In this case there will be more domestic participants with factor loadings exceeding $b_{d}^{\mathcal{D}_{P}}$ entering the market. Some domestic agents with factor loadings less than $b_{d}^{\mathcal{D}_{P}}$ will stop participating.

Suppose now that the initial center of mass is negative, $b_{d}^{\mathcal{D}_{S}}<0$ (the top diagram of Figure 2). The center of mass shifts to the right in this case. Some domestic agents with factor loadings less than $b_{d}^{\mathcal{D}_{P}}$ will enter the market in this case, and some agents with factor loadings exceeding $b_{d}^{\mathcal{D}_{P}}$ will stop participating. 


\subsection{Welfare Analysis}

A move from complete segmentation to partial liberalization affects aggregate welfare through two channels. First, liberalization decision may have a positive or a negative effect on the welfare of each individual agent. Welfare of individual agents is affected because the investment opportunity set changes, and because risky assets are available at prices that are different from the complete segmentation prices. Second, liberalization decision affects the composition of agents in the economy. Some participants may become non-participants, and some non-participants may be drawn to the market.

According to previously introduced classification, in both foreign and domestic markets there are Type B investors who never participate in the risky asset market. For each such agent, indirect utility function does not depend on the set of risky assets and their prices. Partial liberalization, therefore, will have no effect on the utility of each such agent. Liberalization changes prices of risky assets and therefore will affect foreign and domestic investors who participate in the risky asset market. Liberalization will have an effect on investors that always participate (Type A), as well as investors who change their participation decision because liberalization takes place (Type C and Type D).

\subsubsection{Domestic Market}

Type A domestic investors participate in the domestic risky asset market both under partial liberalization and complete segmentation. For an agent of this type welfare is affected because liberalization changes prices of domestic assets. For a type A agent welfare under partial liberalization exceeds the welfare under complete segmentation if and only if the agent's generalized Sharpe ratio increases after liberalization,

$$
\begin{aligned}
S_{P, d}^{2}(h) & >S_{S, d}^{2}(h) \\
\left(\bar{z}_{d}-p_{P, d} R_{d}-a \beta_{d} b_{d}^{h}\right)^{2} & >\left(\bar{z}_{d}-p_{S, d} R_{d}-a \beta_{d} b_{d}^{h}\right)^{2} \\
\left(b_{d}^{\mathcal{D}_{S}} \frac{1}{1+\mathbb{P}^{f}\left(\mathcal{F}_{P}^{p}\right)}-b_{d}^{h}\right)^{2} & >\left(b_{d}^{\mathcal{D}_{S}}-b_{d}^{h}\right)^{2},
\end{aligned}
$$

where the last expression is obtained by substituting the expressions for domestic risk premium and the definitions of the center of mass in the economy. Partial liberalization changes the location 
of the center of mass in the domestic economy. An agent's Sharpe ratio increases and the agent benefits from partial liberalization if there is an increase in the distance between his factor loading and the center of mass (the center of mass moves away from him under partial liberalization). The agent whose factor loading is $b_{d}^{h, 0}=\frac{1}{2}\left(b_{d}^{\mathcal{D}_{P}}+b_{d}^{\mathcal{D}_{S}}\right)$ is indifferent (the utility of this agent does not change with partial liberalization).

It was shown that when initial center of mass is positive it moves to the left under partial liberalization (Figure 2). Therefore, all agents located to the right of the original center of mass $\left(b_{d}^{h}>b_{d}^{\mathcal{D}_{S}}\right)$ will have an increase in utility after partial liberalization. Conversely, all agents located to the left of the original center of mass will have a decrease in utility. If the original center of mass in the economy was negative, then it will move to the right under partial liberalization (top diagram of Figure 2). Then utility increases for the agents located to the left of the original center of mass, and decreases for those located to the right. This established the following result. ${ }^{13}$

Theorem 5 Partial liberalization is not a Pareto-optimal policy in a domestic market with a nonzero (positive or negative) average factor loading.

Is it possible to determine whether there are "more" type A agents who gain than there are those who lose? When factor loadings are uniformly distributed, it is possible to compute the measure of the set of those who gain and of those who lose. The measure is the length of the interval. If the center of mass in the economy is positive so that partial liberalization shifts the center of mass to the left, the set of Type A domestic investors is given by

$$
A[\mathcal{D}]=\left(b_{d}^{\min }, b_{d}^{\mathcal{D}_{P}}-\sqrt{K_{d}}\right) \cup\left(b_{d}^{\mathcal{D}_{S}}+\sqrt{K_{d}}, b_{d}^{\max }\right) .
$$

Then it can be shown that as long as $\mathbb{P}^{f}\left(\mathcal{F}_{P}^{p}\right)>0$, the measure of the set of type A agents whose utility increases is larger than the measure of the set of agents whose utility falls:

$$
\mathbb{P}^{d}\left(b_{d}^{\mathcal{D}_{S}}+\sqrt{K_{d}}, b_{d}^{\max }\right)>\mathbb{P}^{d}\left(b_{d}^{\min }, b_{d}^{\mathcal{D}_{P}}-\sqrt{K_{d}}\right) .
$$

We conclude that under the assumption of a positive center of mass, there are more type A agents who see partial liberalization as a beneficial policy than type A agents whose welfare falls with liberalization.

\footnotetext{
${ }^{13}$ As discussed earlier, the assumption of uniformly distributed factor loadings is not crucial to this non-Pareto optimality result. The result is robust to the choice of the distribution of agent factor loadings.
} 
If the center of mass in the economy is negative, then the set of Type A domestic investors is given by

$$
A[\mathcal{D}]=\left(b_{d}^{\min }, b_{d}^{\mathcal{D}_{S}}-\sqrt{K_{d}}\right) \cup\left(b_{d}^{\mathcal{D}_{P}}+\sqrt{K_{d}}, b_{d}^{\max }\right)
$$

In this case, too, as long as $\mathbb{P}^{f}\left(\mathcal{F}_{P}^{p}\right)>0$, the measure of the set of type A agents whose utility increases is larger than the measure of the set of agents whose utility falls:

$$
\mathbb{P}^{d}\left(b_{d}^{\min }, b_{d}^{\mathcal{D}_{S}}-\sqrt{K_{d}}\right)>\mathbb{P}^{d}\left(b_{d}^{\mathcal{D}_{P}}+\sqrt{K_{d}}, b_{d}^{\max }\right) .
$$

There are "more" Type A agents with an increase in welfare. Does it imply that the aggregate welfare of type A domestic agents is necessarily higher under partial liberalization? The answer is no. There may be more agents with improved utility, but the decline in utility of those who lose may be larger in magnitude, so that the overall effect of partial liberalization may be negative.

Theorem 6 Suppose the center of mass of the domestic economy under complete segmentation is positive, $b_{d}^{\mathcal{D}_{S}}>0$. Then, there exist such domestic and foreign economies that the total utility of domestic investors of Type A decreases after liberalization.

The proof is in the Appendix. The proposition establishes that the aggregate welfare of domestic Type A agents may fall under partial liberalization. The amount by which aggregate welfare falls is a function of the parameters that describe the domestic and foreign economies. For example, the amount of change in aggregate welfare depends on the domestic participation cost, $k_{d}$. The relationship, however, is not monotone and depends on other parameters. Figure $\mathbf{3}$ is a plot of the change in aggregate welfare of domestic Type A investors as a function of $k_{d}$, plotted for three different values of idiosyncratic risk of the domestic asset, $\sigma_{\varepsilon_{d}}^{2}$ (low, intermediate, and high variance). Change in welfare equals welfare under partial liberalization minus welfare under complete segmentation. A higher idiosyncratic variance makes domestic asset less desirable for hedging by domestic agents. Since the asset is relatively less desirable in the cases of higher idiosyncratic risk, the fall in aggregate utility is smaller. When idiosyncratic risk is low and the asset is more desirable the fall in aggregate utility is larger. This corresponds with economic intuition that agents will loose more utility when something with a relatively high economic value (a good hedging asset) becomes less accessible or costs more. When idiosyncratic risk is sufficiently low, there is a monotonic 
relationship between the drop in aggregate welfare and participation cost. Higher participation cost corresponds to a larger drop in welfare.

Figure 4 is a plot of the change in aggregate welfare of Type A domestic agents shown against the foreign participation cost, for three different levels of domestic asset idiosyncratic volatility. In all three cases, the fall in welfare decreases as the foreign participation cost increases. Higher values of $k_{f}$ mean that less foreign agents will enter the market. Since effect on welfare comes from foreign entrants who impact the price, less entrance leads to a smaller negative impact on welfare. Conversely, when foreign investors have a low cost of entrance, the welfare loss of Type A domestic investors is larger.

Aggregate welfare in the domestic economy. It is established already that there is a group of domestic agents whose welfare decreases with partial liberalization. Liberalization has an effect on the welfare of type A, C, and D agents, and does not affect the welfare of type B agents who never participate in the risky asset market. Not only will there be some agents in the domestic economy who are worse off under partial liberalization than under complete segmentation, but a stronger result also obtains. There are non-trivial cases when aggregate welfare in the domestic economy is lower under partial liberalization than under complete segmentation.

Theorem 7 Suppose the center of mass of the domestic economy under complete segmentation is positive, $b_{d}^{\mathcal{D}_{S}}>0$. Then, there exist such domestic and foreign economies that the total utility of domestic investors is lower under partial liberalization than under complete segmentation.

The proof of the theorem is in the Appendix. This result is important because it demonstrates that not only some agents can have lower welfare under liberalization, but the society overall may be worse off. Figure 5 is a plot of the change in aggregate domestic welfare as a function of foreign participation cost, plotted for three different values of domestic asset idiosyncratic risk. The figure shows that the change in welfare is negative: aggregate domestic welfare is higher under complete segmentation than under partial liberalization. For three level of idiosyncratic volatility, the fall in welfare decreases as foreign participation cost increases. When values of $k_{f}$ are higher, less foreign agents will enter domestic market. This leads to a smaller impact on the price of domestic asset and a smaller impact on the aggregate domestic welfare. Similarly to the case of Type A domestic agents, we observe a larger impact on domestic welfare when idiosyncratic risk is low, compared to 
the case when the risk is high. An asset with relatively low idiosyncratic risk provides better hedging and is more desirable. Figure 6 displays the change in aggregate domestic welfare as a function of domestic participation cost, $k_{d}$, for three different values of domestic asset idiosyncratic risk. Similar to previously reported results, the change in welfare is more pronounced when domestic asset has low idiosyncratic risk and provides better hedging.

Impact on individual domestic agents. In a heterogeneous economy partial liberalization has different implications for welfare of different domestic agents. Agents who do not participate in the risky asset market either under segmentation or under partial liberalization will not be affected. Agents who supply, or sell, domestic risky asset will benefit when partial liberalization causes risk premium to fall and the price of the risky asset to rise. At the same time, domestic agents who demand, or purchase, domestic asset will experience a decrease in utility when partial liberalization raises the asset price. It was shown above that the cumulative economy-wide effect is non-trivial, and aggregate welfare under liberalization may be lower than under partial segmentation. Figure 7 is a plot of utility level of domestic agents. The agents' factor loading, $b_{d}^{h}$, is on the $x$-axis and the utility level is on the $y$-axis. Two charts are shown, for the case of complete segmentation and for partial liberalization. Dashed vertical lines show the boundaries between different agent types. Type A agents participate in the risky asset market under both segmentation and liberalization regimes and occupy the extreme left and right regions of the diagram. Type A agents located in the negative half-plane (to the left of the origin) lose utility under liberalization. For these agents utility is higher under segmentation. Type A agents located in the positive half-plane (to the right of the origin) have higher utility under liberalization than under segmentation. In the middle of the diagram there is a group of agents who never participate (Type B). For these agents utility level is the same under segmentation and liberalization, and two graphs coincide. A narrow strip in the negative half-plane, between Type A and Type B agents is the set of agents of Type D. These agents participate in the risky asset market under complete segmentation and do not participate if the economy is liberalized. Their utility is higher when markets are segmented. Finally, a narrow strip in the positive half-plane, to the right of the Type B investors corresponds to Type $\mathrm{C}$ agents. These agents participate only under partial liberalization and their utility is higher under liberalization. 


\subsubsection{Political Economy of Market Liberalizations}

Theorem 7 demonstrates the possibility that a partially liberalized economy may lower the total utility for domestic investors. Whether this happens depends on the political decision of the country. The single factor model with a uniform distribution of factor loading provides a benchmark for the political decision to open under the assumption that the majority of the voters always determines government policy. If agents act economically rationally, the participants will vote to open when their welfare increases after participation and vote to close when their welfare decreases. Rational non-participants will not vote. In an economy with a uniform distribution of factor loadings there will be exactly as many "no" votes as "yes" votes. The area in figure 2 for the participants who lose welfare is exactly equal to the area for participants who gain. While the set of type A agents who gain is larger than those who lose (see discussion following Theorem 5), the number of nonparticipants will increase because of welfare loss and will exactly offsetting the gain in type A agents. Essentially, there equally many agents who desire to pledge future income - those who sell an asset - as agents who desire to buy the asset to receive a payoff in the future. Rational voting will never change this economy.

In a richer and more realistic model, the distribution of factor loadings will not be uniform. If the number of sellers of claims against future income is greater than number of buyers, the economy will have an optimistic outlook to the future. In an optimistic economy, rational voting will be in favor of liberalization. The economy will open to foreigners, the cost of capital will fall and the gain in type A agents will not be offset by the increase in non-participants. It is still possible that the welfare loss from opening will exceed the welfare gain but the majority rules and the economy will open. Note that "optimism" is not a psychological state. We define the word economically where more agents have a demand for selling the asset (negative post-trade holdings, $\boldsymbol{\theta}_{S}^{h p}<0$ ) than agents with positive demand for the asset, $\boldsymbol{\theta}_{S}^{h p}>0$, who need future payoff from the asset to supplement the endowment income.

If the number of sellers of claims is less than the buyers, the economy will have a pessimistic outlook, where the demand for hedging is larger than the supply and agents need to purchase an asset to supplement future endowment payoff to satisfy consumption needs. In this case, the number of agents who lose welfare from opening will exceed the number who gain and the rational majority will vote to close the economy. 
It is clear from the results of this paper that an economy will remain in steady state only when the liberalization status ("open" or "closed") is consistent with the distribution of the factor loadings. This is supported by the findings of Rajan and Zingales (2003) who show that liberalizations have been routinely reversed in developed countries during the 20th century. In particular, many of the reversals happened after the crash of 1929 (see tables 2-5 of their paper) which generated a huge demand for hedging. Countries closed markets to foreigners which, from the view of our paper, was an economically rational response to a re-distribution of factor loadings. While the "interest group" theory of rent-seeking advanced by Rajan and Zingales is consistent with their data, so is a rational economic model with a political system that is governed by a rational majority.

\subsubsection{Economic Significance}

James Madison described a "majority rule" government as the "tyranny of the majority" and most democracies have political mechanisms in place to give strong minorities some influence. If we interpret a strong minority opinion as one where the liberalization decision causes a large welfare loss, then we need to evaluate the significance of changes in welfare. Whether or not the policy of economic openness receives strong and vocal supporters or critics depends on the magnitude of the impact. If the economic significance of the welfare impact is small, then it is not likely that we will observe a strong opposition. If the opposite is true and there is a group of agents who experience a large drop in welfare, we can expect an active political resistance from this group. Of course, the same holds for supporters. Active support for liberalization and even lobbying will emerge when there is a group that stands to gain a significant amount from the policy of open markets.

One method to evaluate economic significance of changes in domestic welfare is to consider percent change in welfare. Figure $\mathbf{8}$ shows percent changes in aggregate domestic welfare as a function of foreign participation fee, $k_{f}$, plotted for three levels of domestic asset idiosyncratic risk. Welfare loss ranges from $4.24 \%$ for a low foreign participation fee to $0.5 \%$ for a very high foreign participation cost and high idiosyncratic risk. This is the loss in aggregate welfare, and utility loss experienced by many agents is compensated in the calculation by the utility gain of the others.

The utility loss or gain experienced by many agents near the extreme values, $b_{d}^{\min }$ and $b_{d}^{\max }$ will be much larger. An aggregate analysis cannot capture strong support or strong resistance coming from individuals or groups, because in the aggregate calculation these two groups cancel each other 
out.

Figure 9 is a plot of percent change in utility level of individual domestic agents. At one extreme, the agents with factor loadings in the neighborhood of $b_{d}^{\min }$ loose $18 \%$ of life-time utility, while agents at the other extreme $b_{d}^{\max }$ gain of $16.7 \%$. For type A (constant participants) in the neighborhood of the A-set boundary, $b_{d}^{\mathcal{D}_{P}}-\sqrt{K_{d}}$, utility loss equals $6.7 \%$. For Type A agents in the neighborhood of another A-set boundary, $b_{d}^{\mathcal{D}_{S}}+\sqrt{K_{d}}$, the gain equals $6.2 \%$. Utility does not change for type B agents. The example shows that a reasonable loss in aggregate utility of $4.24 \%$ is consistent with a significant welfare loss for many individual agents. The aggregate utility calculation cancels utility losses of some agents with utility gains of the others. It is, however, just that, a calculation. Without a mechanism that allows a transfer from the agents who gain to the agents who loose, liberalization policy may find strong opponents in the ranks of those who stand to experience a large welfare loss.

It is easy to see how a minority with large losses in welfare could change government policy when the political system allocates some power to subsets of voters that are less than $50 \%$ of the vote. The welfare loss could be large enough so that the gain experienced by the majority is not sufficient to overcome the political power of the minority. Note that this is not rent-seeking by interest groups. All agents in Figures 8 and 9 are rational traders in an exchange economy. We only need to specify a voting mechanism that allocates some power under some circumstances to welfare-losing minorities to get the outcome that liberalization again depends on the change in factor loadings and the idiosyncratic risk of the risky assets. Economies will rationally change their liberalization policies as these variables change.

We can calculate the equivalent variation measure: Let $\lambda$ be the percentage change in initial wealth such that people enjoy the same level of utility under partial liberalization as under financial autarchy ${ }^{14}$ In the example above when aggregate utility fell by $4.24 \%$, the value of $\lambda$ is 8.4 percent of initial wealth. ${ }^{15}$ For a developed economy this is historically rare and is usually associated with catastrophic events such as wars. Figure $\mathbf{1 0}$ is a plot of equivalent variation in wealth (i.e. $\lambda$ ) as a function of the domestic participation fee assuming that all agents have identical initial wealth. The plot shows the percentage by which initial wealth of the whole economy, and therefore of

\footnotetext{
${ }^{14}$ A similar measure is used in Obstfeld (1994).

${ }^{15}$ This economy has the same parameter values as for Figure 1 , except error variance is $\sigma_{\varepsilon_{d}}^{2}=0.1, b_{d}^{\max }=5.5$; $k_{d}^{d}=0.1$ and $k_{f}^{f}=0.1$.
} 
each agent, must be increased so that the aggregate utility in the economy is the same under the segmentation and partial liberalization. This number is higher in the case when domestic asset has lower idiosyncratic variance and provides better hedging. In this experiment all agents receive the same amount of additional wealth. Although this restores aggregate welfare in the economy, it does not restore welfare of all agents. A change in welfare is different across agents, so the compensation required also varies. Giving the same amount to each agent may restore aggregate welfare, but will not restore welfare of each individual agent. For some increase in wealth will not be sufficient, for the others it will be too large and will increase their welfare by more than the original loss. We compute equivalent variation at the agent level next.

Figure 11 is a plot of equivalent wealth variation for individual domestic agents. Agent factor loading is on the $x$-axis. On the $y$-axis there is percent change in initial wealth that makes the agent indifferent between segmentation and liberalization. The effect is stronger when domestic asset is of higher quality. There are agents whose wealth must be increased by more than $20 \%$ to compensate for welfare loss. For example, consider the previously discussed case of $4.24 \%$ loss in aggregate welfare. In this case some agents loose up to $18 \%$ of their life-time utility. Aggregate wealth must be increased by $8.4 \%$ in this case to return to the aggregate utility level enjoyed under

complete segmentation. Equivalent variation is even higher at individual level. Agents with the largest utility loss (18\%) require an increase in wealth of $34 \%$ so that they enjoy the same level of utility as under segmentation. The calculations illustrate that a minority with substantial loss in welfare can emerge, leading to a visible resistance to liberalization.

\section{Conclusion}

This paper develops a general equilibrium framework for analyzing international financial market segmentation. The model aims at explaining a government's decision to erect an "Iron Curtain" from a political economy standpoint, and not merely view such decisions as the product of rentseeking, agency costs, or irrationality. For an asset pricing model to explain existence of barriers it is necessary to characterize agents who lose when the barriers are removed. We show how this can be done when the standard Consumption CAPM is extended.

The equilibrium framework proposed in the first part of the paper is fairly general. We explicitly 
model the motives of economic agents who issue risky assets and of those who purchase them. The model has three crucial features. First, the costs of being a participant in a risky asset market are incorporated into the model. Second, the participation decision is endogenous. Third, the agents are heterogeneous with respect to their endowment income. We then show that in this setting partial liberalization has non-trivial welfare effects. Allowing foreign investors to purchase domestic securities changes demand for domestic assets, and therefore, their price. This, in turn, affects participation decision of domestic investors. We show how partial liberalization decision can change composition of domestic risky asset market participants and impact their welfare.

In the next part of the paper we consider economies where asset and endowment payoffs are generated by a single factor model. We study difference in welfare of domestic agents under complete segmentation and partial liberalization regimes. There is a group of agents who do not participate in the risky asset market either under segmentation or under liberalization. The welfare of these agents is not affected by the decision to open domestic market to foreign investors. We also identify a group of domestic agents who enter the risky asset market under liberalization. Their utility is higher under liberalization than under segmentation. There also is a group of agents, however, who have higher utility when the markets are segmented. We conclude that partial liberalization is not a Pareto-optimal policy. We go one step further. Not only there is a group of agents who are worse-off under liberalization, but there are also cases when aggregate welfare at home is lower if foreigners are allowed to purchase domestic securities. The welfare loss can be large.

Do we suggest that it is always in a country's best interest to maintain investment barriers? No, we do not. Our model shows the importance of risk sharing. Welfare is decreased when it becomes too costly to participate in the risk sharing provided by the financial market. These conclusions lead to two observations. First, the decision to maintain investment barriers and to prohibit foreigners from purchasing domestic assets may be endogenous and can be regarded by economists as an endogenous variable, and not as an exogenous political outcome. Second, the opening and closing of a country to foreigners is a function of the distribution of risk and of the risk sharing opportunities. Countries with optimistic distributions, where agents are raising capital against future income, will tend to open. Countries with pessimistic distributions, where agents are hedging against future loss will tend to close.

The second observation is directly related to policy recommendations. We argue that countries 
need to prepare well for implementing a liberalization policy. They need to adapt their policies and institutions, and their financial systems. These arguments are similar to those expressed in Fischer (1998), except we employ a theoretical model and can be more specific in identifying causes of welfare loss. A country deliberating liberalization of its financial market must consider several factors and policies. Risk sharing arrangements in the economy constitute one group of important factors. If liberalization makes it more costly for domestic agents to participate in risk sharing, because risky assets are more expensive, then there will be a utility loss among domestic agents. Some domestic agents will even find it too expensive to participate in the liberalized domestic risky asset market and will not hold any risky securities. This calls for policies that are aimed at enhancing risk sharing simultaneously with opening up of domestic markets to foreign investors.

We leave several interesting extensions to further research. The model with entry costs and endogenous participation developed in the first part of this paper can be used to analyze other types of liberalization decisions. For example, it can be adapted to study welfare implications of a policy where domestic firms are allowed to issue equity to foreign investors, but domestic investors are not allowed to purchase foreign assets. The model can also be used to analyze the case of complete liberalization, where foreign and domestic assets are available to both foreign and domestic investors, but different investors face different entry costs. A third extension is to incorporate taxation to study whether there exist re-distribution schemes that can compensate agents for welfare loss. Such studies taken together will enhance our understanding of the political economy of international finance. 


\section{A Appendix: General Theory}

Proposition 1 (Participant in market $m$ ) Under complete segmentation, when participating in the risky asset market $m$ (foreign or domestic), the investor consumes

$$
\begin{aligned}
c_{S, m, 0}^{h p}= & \frac{1}{1+R_{m}}\left[\bar{e}^{h}+\boldsymbol{\theta}_{S, m}^{h \prime}\left[\overline{\mathbf{z}}_{m}-R_{m} \cdot \mathbf{p}_{S, m}\right]+R_{m}\left(W_{0}^{h}-k_{m}\right)-\frac{\ln \delta R_{m}}{a}\right. \\
& \left.-\frac{a}{2}\left[\sigma_{e^{h}}^{2}+\boldsymbol{\theta}_{S, m}^{h \prime} \Sigma_{m} \boldsymbol{\theta}_{S, m}^{h}+2 \boldsymbol{\theta}_{S, m}^{h \prime} \boldsymbol{\sigma}_{e, m}^{h}\right]\right]
\end{aligned}
$$

at time 0 . The vector of optimal post-trade holdings of risky assets is

$$
\boldsymbol{\theta}_{S, m}^{h p}=\frac{1}{a} \Sigma_{m}^{-1}\left(\overline{\mathbf{z}}_{m}-R_{m} \cdot \mathbf{p}_{S, m}-a \boldsymbol{\sigma}_{e, m}^{h}\right) .
$$

The remainder of wealth is invested in

$$
\theta_{S, m, 0}^{h p}=R_{m}\left(W_{0}^{h}-c_{S, m, 0}^{h p}-\mathbf{p}_{S, m}^{\prime} \cdot \boldsymbol{\theta}_{S, m}^{h p}-k_{m}\right)
$$

units of the risk-free bond. Consumption at time 1 equals

$$
\widetilde{c}_{S, m, 1}^{h p}=\widetilde{e}^{h}+\widetilde{\mathbf{z}}_{m}^{\prime} \boldsymbol{\theta}_{S, m}^{h p}+\theta_{S, m, 0}^{h p}
$$

Participant in market $m$. The proof is based on the assumption of CARA preferences and joint Normal distribution of random variables. Using the budget constraint, terminal consumption is

$$
\widetilde{c}_{S, m, 1}^{h p}=\widetilde{e}^{h}+\widetilde{\mathbf{z}}_{m}^{\prime} \boldsymbol{\theta}_{S, m}^{h p}+R_{m}\left(W_{0}^{h}-c_{S, m, 0}^{h p}-\mathbf{p}_{S, m}^{\prime} \cdot \boldsymbol{\theta}_{S, m}^{h p}-k_{m}\right)
$$

Since all random variables are jointly Normally distributed, terminal consumption has a normal distribution with expected value and variance

$$
\begin{aligned}
\mathbb{E}\left[\widetilde{c}_{S, m, 1}^{h p}\right] & =\bar{e}^{h}+\overline{\mathbf{z}}_{m}^{\prime} \cdot \boldsymbol{\theta}_{S, m}^{h p}+R_{m}\left(W_{0}^{h}-c_{S, m, 0}^{h p}-\mathbf{p}_{S, m}^{\prime} \cdot \boldsymbol{\theta}_{S, m}^{h p}-k_{m}\right), \\
\operatorname{Var}\left[\widetilde{c}_{S, m, 1}^{h p}\right] & =\sigma_{e^{h}}^{2}+\boldsymbol{\theta}_{S, m}^{h p \prime} \Sigma_{m} \boldsymbol{\theta}_{S, m}^{h p}+2 \boldsymbol{\theta}_{S, m}^{h p \prime} \cdot \boldsymbol{\sigma}_{e, m}^{h},
\end{aligned}
$$

The optimization problem is solved using the property $z \sim N\left(\mu, \sigma^{2}\right) \Rightarrow \mathbb{E}\left[e^{z}\right]=\exp \left\{\mu+\frac{1}{2} \sigma^{2}\right\}$, and the results follow from the first order conditions.

Proposition 2 (Non-Participant in market $m$ ) Under complete segmentation, when not participating in the risky asset market, the investor consumes

$$
c_{S, m, 0}^{h n}=\frac{1}{1+R_{m}}\left[\bar{e}^{h}+R_{m} W_{0}^{h}-\frac{1}{2} a \sigma_{e^{h}}^{2}-\frac{\ln \delta R_{m}}{a}\right]
$$


and invests the remainder of wealth in

$$
\theta_{S, m, 0}^{h n}=R_{m} W_{0}^{h}-\frac{R_{m}}{1+R_{m}}\left[\bar{e}^{h}+R_{m} W_{0}^{h}-\frac{1}{2} a \sigma_{e^{h}}^{2}-\frac{\ln \delta R_{m}}{a}\right]
$$

units of the risk-free bond. A non-participant's derived utility of wealth is

$$
J_{S, m}^{n}\left[W_{0}^{h}\right]=-\delta\left(1+R_{m}\right) \exp \left[a R_{m} c_{S, m, 0}^{h n}-a\left[\bar{e}^{h}+R_{m} W_{0}^{h}\right]+\frac{a^{2}}{2} \sigma_{e^{h}}^{2}\right] .
$$

Consumption at time 1 equals

$$
\widetilde{c}_{S, m, 1}^{h n}=\widetilde{e}^{h}+\theta_{S, m, 0}^{h n}
$$

Non-Participant in market $m$. The proof is based on the assumption of CARA preferences and joint Normal distribution of random variables. Non-participant in the risky asset market holds risk-free asset. His terminal consumption, therefore, consists of the payoff on the risk-free asset (times the number of shares held), and the payoff on the risky endowment. Terminal consumption of non-participant has a Normal distribution with expected value and variance

$$
\begin{aligned}
\mathbb{E}_{[}\left[\widetilde{c}_{S, m, 1}^{h p}\right] & =\bar{e}^{h}+\theta_{S, m, 0}^{h n}, \\
\operatorname{Var}\left[\widetilde{c}_{S, m, 1}^{h p}\right] & =\sigma_{e^{h}}^{2},
\end{aligned}
$$

The optimization problem is solved using the property $z \sim N\left(\mu, \sigma^{2}\right) \Rightarrow \mathbb{E}\left[e^{z}\right]=\exp \left\{\mu+\frac{1}{2} \sigma^{2}\right\}$, and the results follow from the first order conditions.

Participation criterion under complete segmentation. An agent participates in the risky asset market if and only if the derived utility of wealth under participation exceeds the derived utility of wealth under non-participation,

$$
\begin{aligned}
J_{S, m}^{p}\left[W_{0}^{h}\right] & >J_{S, m}^{n}\left[W_{0}^{h}\right], \\
\frac{S_{S, m}^{2}(h)}{2 a} & >R_{S, m} k_{m},
\end{aligned}
$$

where the last inequality is obtained by using the expressions for indirect utility functions and simplifying.

Under partial liberalization, domestic participant solves the expected utility maximization problem

$$
\begin{aligned}
J_{P, d}^{p}\left[W_{0}^{h}\right] & =\max _{c_{P, d, 0}^{h}, \boldsymbol{\theta}_{P, d}^{h}, \theta_{P, d, 0}^{h}}\left\{-e^{-a c_{P, d, 0}^{h}}-\delta \mathbb{E} e^{-a \widetilde{c}_{P, d, 1}^{h}}\right\} \\
W_{0}^{h} & =c_{P, d, 0}^{h}+\mathbf{p}_{P, d}^{\prime} \cdot \boldsymbol{\theta}_{P, d}^{h}+k_{d}+\theta_{P, d, 0}^{h} / R_{d} .
\end{aligned}
$$


with respect to three decision variables: time 0 consumption $c_{P, 0}^{h}$; time 0 post-trade holdings of risky assets $\boldsymbol{\theta}_{P, d}^{h}$; and time 0 investment in the bond, $\theta_{P, d, 0}^{h}$. The superscript $p$ denotes the values under the optimal policy for a participant and superscript $n$ for non-participant.

Proposition 3 (Domestic Participant Under Partial Liberalization) Under partial liberalization, when participating in the domestic risky asset market the domestic investor consumes

$$
\begin{aligned}
c_{P, d, 0}^{h p}= & \frac{1}{1+R_{d}}\left[\bar{e}^{h}+\boldsymbol{\theta}_{P, d}^{h \prime}\left[\overline{\mathbf{z}}_{d}-R_{d} \cdot \mathbf{p}_{P, d}\right]+R_{d}\left(W_{0}^{h}-k_{d}\right)-\frac{\ln \delta R_{d}}{a}\right. \\
& \left.-\frac{a}{2}\left[\sigma_{e^{h}}^{2}+\boldsymbol{\theta}_{P, d}^{h \prime} \Sigma_{d} \boldsymbol{\theta}_{P, d}^{h}+2 \boldsymbol{\theta}_{P, d}^{h \prime} \boldsymbol{\sigma}_{e, d}^{h}\right]\right]
\end{aligned}
$$

at time 0 . The vector of optimal post-trade holdings of risky assets is

$$
\boldsymbol{\theta}_{P, d}^{h p}=\frac{1}{a} \Sigma_{d}^{-1}\left(\overline{\mathbf{z}}_{d}-R_{d} \cdot \mathbf{p}_{P, d}-a \boldsymbol{\sigma}_{e, d}^{h}\right) .
$$

The remainder of wealth is invested in

$$
\theta_{P, d, 0}^{h p}=R_{d}\left(W_{0}^{h}-c_{P, d, 0}^{h p}-\mathbf{p}_{P, d}^{\prime} \cdot \boldsymbol{\theta}_{P, d}^{h p}-k_{d}\right)
$$

units of the risk-free bond. Consumption at time 1 equals

$$
\widetilde{c}_{P, d, 1}^{h p}=\widetilde{e}^{h}+\widetilde{\mathbf{z}}_{d}^{\prime} \boldsymbol{\theta}_{P, d}^{h p}+\theta_{P, d, 0}^{h p} .
$$

Partial Liberalization: Domestic participant. The proof is based on the assumption of CARA preferences and joint Normal distribution of random variables. Proof proceeds along exactly the same lines as for the participant under complete segmentation.

Proposition 4 (Foreign Participant Under Partial Liberalization) When participating in the partially liberalized risky asset market foreign investor consumes

$$
\begin{aligned}
c_{P, f, 0}^{h p}= & \frac{1}{1+R_{f}}\left[\bar{e}^{h}+\boldsymbol{\theta}_{P, f}^{h \prime}\left[\overline{\mathbf{z}}-R_{f} \cdot \mathbf{p}_{P}\right]+R_{f}\left(W_{0}^{h}-k_{f}\right)-\frac{\ln \delta R_{f}}{a}\right. \\
& \left.-\frac{a}{2}\left[\sigma_{e^{h}}^{2}+\boldsymbol{\theta}_{P, f}^{h \prime} \Sigma \boldsymbol{\theta}_{P, f}^{h}+2 \boldsymbol{\theta}_{P}^{h \prime} \boldsymbol{\sigma}_{e}^{h}\right]\right]
\end{aligned}
$$

at time 0 . The vector of optimal post-trade holdings of risky assets is

$$
\boldsymbol{\theta}_{P, f}^{h p}=\frac{1}{a} \Sigma^{-1}\left(\overline{\mathbf{z}}-R_{f} \cdot \mathbf{p}_{P}-a \boldsymbol{\sigma}_{e}^{h}\right)
$$


The remainder of wealth is invested in

$$
\theta_{P, f, 0}^{h p}=R_{f}\left(W_{0}^{h}-c_{P, f, 0}^{h p}-\mathbf{p}_{P}^{\prime} \cdot \boldsymbol{\theta}_{P, f}^{h p}-k_{f}\right)
$$

units of the risk-free bond. Consumption at time 1 equals

$$
\widetilde{c}_{P, f, 1}^{h p}=\widetilde{e}^{h}+\widetilde{\mathbf{z}}^{\prime} \boldsymbol{\theta}_{P, f}^{h p}+\theta_{P, f, 0}^{h p} .
$$

Proof. The proof is based on the assumption of CARA preferences and joint Normal distribution of random variables. Proof proceeds along exactly the same lines as for the participant under complete segmentation.

\section{B Appendix: Single Factor Model}

\section{B.1 Complete Segmentation}

Generalized Sharpe Ratio. The expression for $S_{S, m}^{2}(h)$ is obtained by direct computation. For all domestic investors, $h \in \mathcal{D}, \operatorname{Cov}\left(\widetilde{e}^{h}, \widetilde{z}_{d}\right)=b_{d}^{h} \cdot \beta_{d}$, and $\operatorname{Cov}\left(\widetilde{e}^{h}, \widetilde{z}_{f}\right)=0$. For all foreign investors, $h \in \mathcal{F}, \operatorname{Cov}\left(\widetilde{e}^{h}, \widetilde{z}_{f}\right)=b_{f}^{h} \cdot \beta_{f}$, and $\operatorname{Cov}\left(\widetilde{e}^{h}, \widetilde{z}_{d}\right)=0$. Also, $\Sigma_{m}^{-1}=1 / \operatorname{Var}\left(\widetilde{z}_{m}\right)$.

$$
\begin{aligned}
S_{S, m}^{2}(h) & =\left(\bar{z}_{m}-R_{m} \cdot p_{S, m}-a \cdot b_{m}^{h} \cdot \beta_{m}\right)^{2} /\left(\beta_{m}^{2}+\sigma_{\varepsilon_{m}}^{2}\right) \\
& =a^{2} \frac{\beta_{m}^{2}}{\beta_{m}^{2}+\sigma_{\varepsilon_{m}}^{2}}\left[b_{m}^{\mathcal{M}_{S}}-b_{m}^{h}\right]^{2}>2 a R_{m} k_{m} \\
b_{m}^{\mathcal{M}_{S}} & \equiv \frac{1}{\mathbb{P}^{m}\left(\mathcal{M}_{S}\right)} \int_{\mathcal{M}_{S}} b_{m}^{h} d \mathbb{P}^{m}(h)
\end{aligned}
$$

\section{B.2 Partial Liberalization}

Computation of $\mathbb{P}^{d}\left(\mathcal{D}_{P}^{p}\right)$. For uniform distribution $b_{d}^{h} \sim \operatorname{Uniform}\left(b_{d}^{\min }, b_{d}^{\max }\right), P D F^{d}\left(b_{d}^{h}\right)=$ $1 /\left(b_{d}^{\max }-b_{d}^{\min }\right)$, by direct computation:

$$
\begin{aligned}
\mathbb{P}^{d}\left(\mathcal{D}_{P}^{p}\right) & =\int_{\mathcal{D}_{P}^{p}} d \mathbb{P}^{d}(h)=\int_{\mathcal{D}_{P}^{p}} P D F^{d}\left(b_{d}^{h}\right) d b_{d}^{h} \\
& =\int_{b_{d}^{\min }}^{b_{d}^{h *}} \frac{1}{b_{d}^{\max }-b_{d}^{\min }} d b_{d}^{h}+\int_{b_{d}^{h * *}}^{b_{d}^{\max }} \frac{1}{b_{d}^{\max }-b_{d}^{\min }} d b_{d}^{h} \\
& =1-\frac{2 \sqrt{2 a R_{d} k_{d} \operatorname{Var}\left[\widetilde{z}_{d}\right]}}{a \beta_{d}\left(b_{d}^{\max }-b_{d}^{\min }\right)}
\end{aligned}
$$


This gives $\mathbb{P}^{d}\left(\mathcal{D}_{P}^{p}\right)$ in terms of the price of the domestic risky asset, $p_{P, d}$ (a quantity determined in equilibrium) and other parameters of the problem.

\section{Computation of covariance:}

$$
\begin{aligned}
\operatorname{Cov}\left[\widetilde{z}_{d}, \widetilde{e}^{p} P_{P}\right] & =\int_{\mathcal{D}_{P}^{p}} \operatorname{Cov}\left[\widetilde{z}_{d}, \widetilde{e}^{h}\right] d \mathbb{P}^{d}(h)=\int_{\mathcal{D}_{P}^{p}} b_{d}^{h} \beta_{d} \cdot \frac{1}{b_{d}^{\max }-b_{d}^{\min }} d b_{d}^{h} \\
& =\beta_{d} \frac{b_{d}^{\min }+b_{d}^{\max }}{2}-\frac{2\left(\bar{z}_{d}-R_{d} p_{P, d}\right) \sqrt{2 a R_{d} k_{d} \operatorname{Var}\left[\widetilde{z}_{d}\right]}}{\beta_{d} a^{2}\left(b_{d}^{\max }-b_{d}^{\min }\right)}
\end{aligned}
$$

\section{Generalized Sharpe Ratio:}

$$
\begin{aligned}
S_{P}^{2}(h) & =\frac{1}{\operatorname{Var}\left[\widetilde{z}_{d}\right]}\left(\bar{z}_{d}-R_{f} p_{P, d}-a \operatorname{Cov}\left[\widetilde{e}^{h}, \widetilde{z}_{d}\right]\right)^{2}+\frac{1}{\operatorname{Var}\left[\widetilde{z}_{f}\right]}\left(\bar{z}_{f}-R_{f} p_{P, f}-a \operatorname{Cov}\left[\widetilde{e}^{h}, \widetilde{z}_{f}\right]\right)^{2} \\
& =\frac{1}{\operatorname{Var}\left[\widetilde{z}_{d}\right]}\left(\bar{z}_{d}-R_{f} p_{P, d}\right)^{2}+\frac{1}{\operatorname{Var}\left[\widetilde{z}_{f}\right]}\left(\bar{z}_{f}-R_{f} p_{P, f}-a b_{f}^{h} \beta_{f}\right)^{2} .
\end{aligned}
$$

\section{Computation of price of the foreign asset, $p_{P, f}$.}

Remark 8 In general, suppose $A>0$ and $x_{1}=\frac{B}{A}-\frac{\sqrt{C}}{A}, x_{2}=\frac{B}{A}+\frac{\sqrt{C}}{A}$ so that $x_{1} \leq x_{2}$, then

$$
\begin{aligned}
\int_{b^{\min }}^{x_{1}} \frac{1}{b^{\max }-b^{\min }} d b+\int_{x_{2}}^{b^{\max }} \frac{1}{b^{\max }-b^{\min }} d b & =1-\frac{2 \sqrt{C}}{A\left(b^{\max }-b^{\min }\right)} \\
\int_{b^{\min }}^{x_{1}} \frac{b}{b^{\max }-b^{\min }} d b+\int_{x_{2}}^{b^{\max }} \frac{b}{b^{\max }-b^{\min }} d b & =\frac{b^{\max }+b^{\min }}{2}-\frac{2 B \sqrt{C}}{A \cdot A\left[b^{\max }-b^{\min }\right]}
\end{aligned}
$$

Then, compute

$$
\begin{aligned}
\mathbb{P}^{f}\left(\mathcal{F}_{P}^{p}\right) & =1-\frac{2 \sqrt{C}}{A\left(b_{f}^{\max }-b_{f}^{\min }\right)} \\
\operatorname{Cov}\left[\widetilde{z}_{f}, \widetilde{e}_{P}^{\left.\mathcal{F}_{P}^{p}\right]}\right. & =\beta_{f} \frac{b^{\max }+b^{\min }}{2}-\beta_{f} \frac{2 B \sqrt{C}}{A \cdot A\left[b_{f}^{\max }-b_{f}^{\min }\right]} \\
A & \equiv a \beta_{f} \sqrt{\operatorname{Var}\left[\widetilde{z}_{d}\right]} \\
B & \equiv \sqrt{\operatorname{Var}\left[\widetilde{z}_{d}\right]}\left(\bar{z}_{f}-R_{f} p_{P, f}\right) \\
\sqrt{C} & \equiv \sqrt{\operatorname{Var}\left[\widetilde{z}_{f}\right]} \sqrt{2 a R_{f} k_{f} \operatorname{Var}\left[\widetilde{z}_{d}\right]-\left(\bar{z}_{d}-R_{f} p_{P, d}\right)^{2}}
\end{aligned}
$$

The price of foreign asset,

$$
p_{P, f}=\frac{1}{R_{f}}\left[\bar{z}_{f}-\frac{a \operatorname{Cov}\left[\widetilde{z}_{f}, \widetilde{e}_{P}^{p}\right]}{\mathbb{P}^{f}\left(\mathcal{F}_{P}^{p}\right)}\right] \Rightarrow\left[\bar{z}_{f}-p_{P, f} R_{f}\right] \mathbb{P}^{f}\left(\mathcal{F}_{P}^{p}\right)=a \operatorname{Cov}\left[\widetilde{z}_{f}, \widetilde{e}^{p}\right]
$$




$$
\begin{aligned}
{\left[\bar{z}_{f}-p_{P, f} R_{f}\right] } & =\frac{2\left[\bar{z}_{f}-p_{P, f} R_{f}\right] \sqrt{C}}{A\left(b_{f}^{\max }-b_{f}^{\min }\right)}+a \beta_{f} \frac{b^{\max }+b^{\min }}{2}-a \beta_{f} \frac{2 B \sqrt{C}}{A \cdot A\left[b_{f}^{\max }-b_{f}^{\min }\right]} \\
& =a \beta_{f} \frac{b^{\max }+b^{\min }}{2}+\frac{2\left[\left[\bar{z}_{f}-p_{P, f} R_{f}\right] A-a \beta_{f} B\right] \sqrt{C}}{A \cdot A\left(b_{f}^{\max }-b_{f}^{\min }\right)} \\
& =a \beta_{f} \frac{b^{\max }+b^{\min }}{2}+\frac{2 \sqrt{\operatorname{Var}\left[\widetilde{z}_{d}\right]}\left(\bar{z}_{f}-p_{P, f} R_{f}\right)\left[a \beta_{f}-a \beta_{f}\right] \sqrt{C}}{A \cdot A\left(b_{f}^{\max }-b_{f}^{\min }\right)} \\
& =a \beta_{f} \frac{b^{\max }+b^{\min }}{2} .
\end{aligned}
$$

\section{Domestic Asset Price:}

$$
\begin{aligned}
p_{P, d} & =\frac{\bar{z}_{d} \mathbb{P}^{d}\left(\mathcal{D}_{P}^{p}\right)+\bar{z}_{d} \mathbb{P}^{f}\left(\mathcal{F}_{P}^{p}\right)-a \operatorname{Cov}\left[\widetilde{z}_{d}, \widetilde{e}^{p}\right]-a \operatorname{Cov}\left[\widetilde{z}_{d}, \widetilde{e}^{p} \mathcal{F}_{P}^{p}\right]}{R_{d} \mathbb{P}^{d}\left(\mathcal{D}_{P}^{p}\right)+R_{f} \mathbb{P}^{f}\left(\mathcal{F}_{P}^{p}\right)} \\
& =\frac{\bar{z}_{d} \mathbb{P}^{d}\left(\mathcal{D}_{P}^{p}\right)+\bar{z}_{d} \mathbb{P}^{f}\left(\mathcal{F}_{P}^{p}\right)-a \operatorname{Cov}\left[\widetilde{z}_{d}, \widetilde{e}^{\mathcal{D}_{P}^{p}}\right]}{R_{d} \mathbb{P}^{d}\left(\mathcal{D}_{P}^{p}\right)+R_{f} \mathbb{P}^{f}\left(\mathcal{F}_{P}^{p}\right)} \\
& \Rightarrow\left(p_{P, d} R_{d}-\bar{z}_{d}\right)=-a \beta_{d} \frac{b_{d}^{\min }+b_{d}^{\max }}{2}+\left[\bar{z}_{d}-p_{P, d} R_{f}\right] \mathbb{P}^{f}\left(\mathcal{F}_{P}^{p}\right)
\end{aligned}
$$

where we use previously derived expressions for $\mathbb{P}^{d}\left(\mathcal{D}_{P}^{p}\right)$ and $\operatorname{Cov}\left[\widetilde{z}_{d}, \widetilde{e}^{\mathcal{D}_{P}^{p}}\right], \operatorname{Cov}\left[\widetilde{z}_{d}, \widetilde{e}_{P}^{p}\right]=0$. Since $R_{f}=R_{d}$,

$$
\bar{z}_{d}-p_{P, d} R_{d}=a \beta_{d} \frac{b_{d}^{\min }+b_{d}^{\max }}{2\left[1+\mathbb{P}^{f}\left(\mathcal{F}_{P}^{p}\right)\right]}
$$

\section{B.3 Welfare: Domestic Investors}

Analysis of Type A investors. Type A domestic investors participate in the domestic risky asset market before and after partial liberalization. For such investors,

$$
\begin{aligned}
& J_{S, d}^{p}\left[W_{0}^{h}\right]=J_{S, d}^{n}\left[W^{h}\right] \exp \left\{-\frac{a}{1+R_{d}}\left[\frac{S_{S, d}^{2}(h)}{2 a}-k_{d} R_{d}\right]\right\}, \\
& J_{P, d}^{p}\left[W_{0}^{h}\right]=J_{S, d}^{n}\left[W^{h}\right] \exp \left\{-\frac{a}{1+R_{d}}\left[\frac{S_{P, d}^{2}(h)}{2 a}-k_{d} R_{d}\right]\right\} .
\end{aligned}
$$

For an agent of this type, welfare under partial liberalization exceeds the welfare under complete segmentation if and only if,

$$
\begin{aligned}
J_{P, d}^{p}\left[W_{0}^{h}\right] & \geq J_{S, d}^{p}\left[W_{0}^{h}\right] \Longleftrightarrow S_{P, d}^{2}(h) \geq S_{S, d}^{2}(h) \\
\left(\bar{z}_{d}-p_{P, d} R_{d}-a \beta_{d} b_{d}^{h}\right)^{2} & \geq\left(\bar{z}_{d}-p_{S, d} R_{d}-a \beta_{d} b_{d}^{h}\right)^{2}
\end{aligned}
$$


Proof (Aggregate Welfare of Type A Domestic Agents). The Theorem states that if the center of mass of the domestic economy under complete segmentation is positive, $b_{d}^{\mathcal{D}_{S}}>0$, there exist such domestic and foreign economies that the total utility of domestic investors of Type A decreases with partial liberalization.

To prove that such case exists it is sufficient to provide one example. Aggregate welfare of Type A domestic investors decreases in the following numerical example. Parameter values are: $a=0.5$, $\delta=0.99$. Domestic economy: $b_{d}^{\min }=-4, b_{d}^{\max }=5$; For all $\forall h \in \mathcal{D}: \bar{e}^{h}=b_{d}^{h}, W_{0}^{h}=2, \sigma_{\varepsilon_{d}^{h}}^{2}=1$; $k_{d}=0.55, R_{d}=1, \bar{z}_{d}=1, \beta_{d}=1, \sigma_{\varepsilon_{d}}^{2}=1$. Foreign economy: $b_{f}^{\min }=-2, b_{f}^{\max }=4$; For all $\forall h \in \mathcal{F}: \bar{e}^{h}=b_{f}^{h}, W_{0}^{h}=2, \sigma_{\varepsilon_{f}^{h}}^{2}=1 ; k_{f}=0.01, R_{f}=1, \bar{z}_{f}=1, \beta_{f}=1, \sigma_{\varepsilon_{f}}^{2}=1$. Segmented and partial liberalization equilibria in the domestic market are:

$$
\begin{aligned}
p_{S, d} & =0.75, \quad \mathcal{D}_{S, d}=(-4,-1.59762) \cup(2.59762,5), \\
p_{P, d} & =0.872406, \quad \mathcal{D}_{P, d}=(-4,-1.84243) \cup(2.35281,5) . \\
A[\mathcal{D}] & =(-4,-1.84243) \cup(2.59762,5) .
\end{aligned}
$$

In this example, aggregate welfare of Type A domestic investors falls after partial liberalization,

$$
\mathbb{J}_{S, d}=-10.5939>\mathbb{J A}_{P, d}=-10.9122 .
$$

This is no the only possible set of parameter values. There are infinitely many economies in which the theorem holds. Q.E.D.

Remark (Aggregate Welfare of Type A Domestic Agents). We briefly comment on the difficulty of analytical characterization of aggregate utility in the model.

Definition 9 The error function $\operatorname{erf}(z)$ is the integral of the Gaussian distribution,

$$
\operatorname{erf}(z)=\frac{2}{\sqrt{\pi}} \int_{0}^{z} e^{-t^{2} d t}
$$

The following relationships hold:

$$
\lim _{z \rightarrow+\infty} \operatorname{erf}(z)=1, \quad \operatorname{erf}(y)=2 \Phi(\sqrt{2} \cdot y)-1,
$$

where $\Phi(\cdot)$ is the standard Normal cumulative density function. The imaginary error function $\operatorname{erf} i(z)$ is defined as

$$
\operatorname{erf} i(z) \equiv \operatorname{erf}(z \cdot i) / i
$$


To compute aggregate welfare for a set of participants we need to integrate the individual's indirect utility function over the set. For example, total utility of domestic Type A agents under segmentation, $\mathbb{J} \mathbb{A}_{S, d}$, is given by

$$
\mathbb{J}_{S, d}=\left[\int_{b_{d}^{\min }}^{b_{d}^{\mathcal{D}_{P}}-\sqrt{K_{d}}} \frac{J_{S, d}^{p}\left[W_{0}^{h}\right]}{b_{d}^{\max }-b_{d}^{\min }} d b_{d}^{h}+\int_{b_{d}^{\mathcal{D}_{S}}+\sqrt{K_{d}}}^{b_{d}^{\max }} \frac{J_{S, d}^{p}\left[W_{0}^{h}\right]}{b_{d}^{\max }-b_{d}^{\min }} d b_{d}^{h}\right] .
$$

This integral cannot be expressed in terms of elementary (analytic) functions. The structure of the integral as the same as the integral over the Normal density, which, too, does not have an analytic expression. To see this, observe that the function $J_{S, d}^{p}\left[W_{0}^{h}\right]$ is proportional to the term that has the same structure as the Normal density:

$$
J_{S, d}^{p}\left[W_{0}^{h}\right] \propto \exp \left\{-\frac{a}{1+R_{d}}\left[b_{d}^{h}-\frac{a}{2}\left(b_{d}^{h}\right)^{2}+\frac{1}{2 a} S_{S, d}^{2}(h)\right]\right\} .
$$

Just as an integral of the Normal density over a set can be written using the error function, the integral of the indirect utility function can be written using $\operatorname{Erfi}(\cdot)$.

Integration of utility of non-participants. In the single factor model, expected endowment payoff is $\bar{e}^{h}=b_{m}^{h}$. Integrating derived utility of wealth over an interval (a set of agents) yields:

$$
\begin{aligned}
\int_{A}^{B} \frac{J_{P, m}^{n}\left[W^{h}\right]}{b_{m}^{\max }-b_{m}^{\min }} d b_{m}^{h}= & \frac{\delta\left(1+R_{m}\right)^{3 / 2}}{a\left(b_{m}^{\max }-b_{m}^{\min }\right)} \sqrt{\frac{\pi}{2}} \times \exp \left[-\frac{1+2 a R_{m} W_{0}^{h}-a^{2} \sigma_{\varepsilon_{m}^{h}}^{2}+2 R_{m} \ln \delta R_{m}}{2\left(1+R_{m}\right)}\right] \\
& \times\left[\operatorname{Erfi}\left(\frac{-1+a \cdot A}{\sqrt{2\left(1+R_{m}\right)}}\right)-\operatorname{Erfi}\left(\frac{-1+a \cdot B}{\sqrt{2\left(1+R_{m}\right)}}\right)\right] .
\end{aligned}
$$

Integration of utility of participants (under segmentation). In the single factor model, expected endowment payoff is $\bar{e}^{h}=b_{m}^{h}$. Integrating derived utility of wealth over an interval (a set of agents) yields:

$$
\begin{aligned}
& \int_{A}^{B} \frac{J_{S, m}^{p}\left[W^{h}\right]}{b_{m}^{\max }-b_{m}^{\min }} d b_{m}^{h} \\
= & \frac{\delta\left(1+R_{m}\right)^{3 / 2}}{a\left(b_{m}^{\max }-b_{m}^{\min }\right)} \sqrt{\frac{\pi}{2}} \sqrt{\frac{\beta_{m}^{2}+\sigma_{\varepsilon_{m}}^{2}}{\sigma_{\varepsilon_{m}}^{2}}} \times \exp \left\{-\frac{a}{1+R_{m}}\left[R_{m}\left(W_{0}^{h}-k_{m}\right)+\frac{R_{m} \ln \delta R_{m}}{a}\right]\right\} \\
& \times \exp \left\{\frac{a^{2}}{2\left(1+R_{m}\right)} \sigma_{\varepsilon_{m}^{h}}^{2}\right\} \times \exp \left\{-\frac{\left(-1+a b_{m}^{\mathcal{M}_{S, m}}\right) \beta_{m}^{2}+\sigma_{\varepsilon_{m}}^{2}}{2\left(1+R_{m}\right) \sigma_{\varepsilon_{m}}^{2}}\right\} \\
& \times\left[\operatorname{Erfi}\left[\frac{\left(-1+a b_{m}^{\mathcal{M}_{S, m}}\right) \beta_{m}^{2}+(-1+a \cdot A) \sigma_{\varepsilon_{m}}^{2}}{\sqrt{2\left(1+R_{m}\right) \sigma_{\varepsilon_{m}}^{2}\left(\beta_{m}^{2}+\sigma_{\varepsilon_{m}}^{2}\right)}}\right]-\operatorname{Erfi}\left[\frac{\left(-1+a b_{m}^{\mathcal{M}_{S, m}}\right) \beta_{m}^{2}+(-1+a \cdot B) \sigma_{\varepsilon_{m}}^{2}}{\sqrt{2\left(1+R_{m}\right) \sigma_{\varepsilon_{m}}^{2}\left(\beta_{m}^{2}+\sigma_{\varepsilon_{m}}^{2}\right)}}\right]\right] .
\end{aligned}
$$


A similar expression holds for the case of partial liberalization. For example, to obtain the expression for integration of utility of domestic participants under liberalization $(m=d)$, replace $b_{m}^{\mathcal{M}_{S, m}}$ in the expression above with $b_{d}^{\mathcal{D}_{P}}$.

Proof (Aggregate Welfare of Domestic Agents). The Theorem states that if the center of mass of the domestic economy under complete segmentation is positive, $b_{d}^{\mathcal{D}_{S}}>0$, there exist such domestic and foreign economies that the total utility of domestic investors is lower under partial liberalization than under complete segmentation.

To prove that such case exists it is sufficient to provide one example. In the following numerical example aggregate welfare of domestic investors is lower under partial liberalization than under complete segmentation. Parameter values are: $a=0.5, \delta=0.99$. Domestic economy: $b_{d}^{\min }=-4$, $b_{d}^{\max }=5.5 ;$ For all $\forall h \in \mathcal{D}: \bar{e}^{h}=b_{d}^{h}, W_{0}^{h}=2, \sigma_{\varepsilon_{d}^{h}}^{2}=1 ; k_{d}=0.55, R_{d}=1, \bar{z}_{d}=1, \beta_{d}=1, \sigma_{\varepsilon_{d}}^{2}=0.1$ (this is relatively low level of domestic asset idiosyncratic risk). Foreign economy: $b_{f}^{\min }=-2$, $b_{f}^{\max }=4 ;$ For all $\forall h \in \mathcal{F}: \bar{e}^{h}=b_{f}^{h}, W_{0}^{h}=2, \sigma_{\varepsilon_{f}^{h}}^{2}=1 ; k_{f}=0.1, R_{f}=1, \bar{z}_{f}=1, \beta_{f}=1, \sigma_{\varepsilon_{f}}^{2}=1$. Segmented and partial liberalization equilibria in the domestic market are:

$$
\begin{aligned}
p_{S, d} & =0.625 \\
\mathcal{D}_{S, d} & =(-4,-0.805635) \cup(2.30563,5.5) \\
p_{P, d} & =0.788 \\
\mathcal{D}_{P, d} & =(-4,-1.13204) \cup(1.97923,5.5)
\end{aligned}
$$

In this example, aggregate welfare of domestic investors is lower under partial liberalization than under complete segmentation.

$$
\mathbb{J}_{S, d}=-13.4421>\mathbb{J}_{P, d}=-14.0126 .
$$

This is no the only possible set of parameter values. There are infinitely many economies in which the theorem holds. Q.E.D. 


\section{References}

[1] Adler, M. and B. Dumas, 1975, Optimal international acquisitions, Journal of Finance 30, $1-19$.

[2] Adler, M. and B. Dumas, 1983, International Portfolio Choice and Corporation Finance: A Synthesis, Journal of Finance 38, 925-984.

[3] Alexander, Gordon, Cheol Eun, and Sundaram Janakiramanan, 1987, Asset pricing and dual listing on foreign capital markets: A note, Journal of Finance 42, 151-158.

[4] Basak, Suleyman, 1996, "An Intertemporal Model of International Capital Market Segmentation," The Journal of Financial and Quantitative Analysis, Vol. 31, No. 2, 161-188.

[5] Basak, Suleyman, and Domenico Cuoco, 1998, "An Equilibrium Model with Restricted Stock Market Participation," The Review of Financial Studies 11, 309-341.

[6] Bekaert, Geert, 1995, Market integration and investment barriers in emerging equity markets, World Bank Economic Review 9, 75-107.

[7] Bekaert, Geert, and Campbell R. Harvey, 1995, Time-varying world market integration, Journal of Finance 50, 403-444.

[8] Bekaert, Geert, and Campbell R. Harvey, 1997, Emerging equity market volatility, Journal of Financial Economics 43. 29-77.

[9] Bekaert, Geert, and Campbell R. Harvey, 2000, Foreign speculators and emerging equity markets, Journal of Finance 55, 565-613.

[10] Bekaert, Geert, Campbell R. Harvey, Christian Lundblad, "Does Financial Liberalization Spur Growth?" NBER Working Paper No. 8245, 2001.

[11] Bennett, James, and Leslie Young, 1999, "International Stock Market Equilibrium with Heterogenous Tastes," The American Economic Review, Vol. 89, No. 3, 639-648.

[12] Bhagwati, Jagdish. "The Capital Myth," Foreign Affairs, May/June 1998, pp. 7-12. 
[13] F. Black. "International Capital Market Equilibrium with Investment Barriers." Journal of Financial Economics 1 (December 1974), 337-352.

[14] Boubakri, Narjess, and Jean-Claude Cosset, 1998, The financial and operating performance of newly privatized firms: Evidence from developing countries, Journal of Finance 53, 1081-1111.

[15] Buckberg, Elaine, 1995, Emerging stock markets and international asset pricing. World Bank Economic Review 9, 51-74.

[16] Chari, Anusha and Henry, Peter Blair. "Capital Account Liberalization: Allocative Efficiency or Animal Spirits," NBER Working Paper No. 8908, 2002a.

[17] Chari, Anusha and Henry, Peter Blair. "Risk Sharing and Asset Prices: Evidence From a Natural Experiment." Stanford University Working Paper, 2002b.

[18] Chen, Zhiwu and Peter J. Knez, 1995, "Measurement of Market Integration and Arbitrage," The Review of Financial Studies 8, 287-325.

[19] Clarke, George, Robert Cull, Maria Soledad Martinez Peria, and Susana M. Sánchez, 2003, "Foreign Bank Entry: Experience, Implications for Developing Economies, and Agenda for Further Research," The World Bank Research Observer 18, 25-59.

[20] Clarke, George, Robert Cull, Maria Soledad Martinez Peria, and Susana M. Sánchez, 2004, "Bank Lending to Small Businesses in Latin America: Does Bank Origin Matter?" Journal of Money, Credit, and Banking, forthcoming.

[21] Dow, J., and G. Gorton, 1997, "Noise Trading, Delegated Portfolio Management, and Economic Welfare," Journal of Political Economy, 105, 1024-1050.

[22] Dumas, Bernard and Raman Uppal, 2001, "Global Diversification, Growth, and Welfare with Imperfectly Integrated Markets for Goods," Review of Financial Studies 14, 277-305.

[23] Edison, Hali, Michael Klein, Luca Ricci, and Torsten, Sloek, "Capital Account Liberalization and Economic Performance: Survey and Synthesis," NBER WP\# 9100, 2002.

[24] Errunza, Vihang, and Etienne Losq, 1985, International asset pricing under mild segmentation: Theory and test, Journal of Finance 40, 105-124. 
[25] Errunza, Vihang, and Etienne Losq, 1989, Capital flow controls, international asset pricing, and investors welfare: A multi-country framework, Journal of Finance 44, 1025-1037.

[26] Errunza, Vihang, and Etienne Losq, and Prasad Padmanabhan, 1992, Tests of integration, mild segmentation, and segmentation hypotheses, Journal of Banking and Finance 16, 949972.

[27] Errunza, Vihang, and Darius Miller, 2000, Market segmentation and the cost of capital in international equity markets, Journal of Financial and Quantitative Analysis 35(4).

[28] Errunza, V. and L. Senbet, 1981, The effects of international operations on the market value of the firm: Theory and evidence, Journal of Finance 36, 401-417.

[29] Errunza, Vihang, Lemma Senbet, and Ked Hogan. "The pricing of country funds from emerging markets: Theory and Evidence." International Journal of Theoretical and Applied Finance 1 (1998) 111-143.

[30] Eun, Cheol, and Sundaram Janakiramanan, 1986, A model of international asset pricing with a constraint on foreign equity ownership, Journal of Finance 41, 897-914.

[31] Feldstein, Martin, and David Hartman, 1979, "The Optimal Taxation of Foreign Source Investment Income," The Quarterly Journal of Economics 93, 613-629.

[32] Fischer, Stanley, "Capital Account Liberalization and the Role of the IMF," Princeton Essays in International Finance, 207, 1998, pp. 1-10.

[33] Foerster, Stephen, R., and G. Andrew Karolyi, 1999, The effects of market segmentation and investor recognition on asset prices: Evidence from foreign stocks listing in the United States, Journal of Finance 54, 981-1013.

[34] Goetzmann, William N., Ukhov, Andrey and Zhu, Ning, "China and the World Financial Markets 1870-1930: Modern Lessons From Historical Globalization (English Version)" (October 2001). Yale ICF Working Paper No. 00-62. http://ssrn.com/abstract=289139

[35] Gourinchas, Pierre Olivier and Olivier Jeanne, "On the Benefits of Capital Account Liberalization," Princeton University Working paper. 
[36] Grauer, F. L., R. H. Litzenberger, and R. E. Stehle, 1976, Sharing rules and equilibrium in an international capital market under uncertainty, Journal of Financial Economics 3, 233-256.

[37] Hargis, Kent, 2002, "Forms of Foreign Investment Liberalization and Risk in Emerging Stock Markets," Journal of Financial Research, Spring 2002.

[38] Henry, P., 2000a, Stock Market Liberalization, Economic Reform, and Emerging Market Equity Prices, Journal of Finance 55, 529-564

[39] Henry, P., 2000b, Do Stock Market Liberalizations Cause Investment Booms, Journal of Financial Economics

[40] Henry, Peter Blair, 2003, "Capital Account Liberalization, The Cost of Capital, and Economic Growth," American Economic Review

[41] Henry, Peter Blair, "Commentary on Bekaert, Harvey, and Lundbald's 'Equity Market Liberalization in Emerging Equity Markets"' (January 2003). Stanford GSB Working Paper No. 1783. http://ssrn.com/abstract $=381282$

[42] Hietala, P.K., 1989, "Asset Pricing in Partially Segmented Markets: Evidence from the Finnish Market," Journal of Finance, 44, 697-715.

[43] Jorion, Philippe, and William N. Goetzmann, 1999, "Global Stock Markets in the Twentieth Century," The Journal of Finance, 54, 953-980.

[44] Kaminsky, Garciela Laura, and Sergio L. Schmukler, 2004, "Short-Run Pain, Long-Run Gain: The Effects of Financial Liberalization," World Bank Working Paper 2912, also NBER Working Paper 9787.

[45] Kim, E.H., V. Singal, "Stock Market Openings: Experience of Emerging Economies," Journal of Business, 73, 2000, pp. 25-66.

[46] McKinnon, Ronald I. The Order of Economic Liberalization. Johns Hopkins University Press, Baltimore, 1991. 
[47] Obstfeld, Maurice. "How Integrated Are World Capital Markets? Some New Tests," in Guillermo Calvo, Ronald Findlay, Pentti Kouri, and Jorge Braga de Macedo, eds. Debt, stabilization and development: Essays in memory of Carlos Diaz-Alejandro. Oxford: Blackwell, 1989, pp. $134-55$.

[48] Obstfeld, Maurice. "Risk-taking, global diversification, and growth," American Economic Review 84, 1994, pp. 1310-29.

[49] Patro, Dilip K., and John K. Wald, 2004, "Firm Characteristics and the Impact of Emerging Market Liberalizations," Journal of Banking and Finance, forthcoming.

[50] Peria, Maria Soledad Martinez, and Ashoka Mody, 2004, "How Foreign Participation and Market Concentration Impact Bank Spreads: Evidence from Latin America," Journal of Money, Credit, and Banking, forthcoming.

[51] Rajan, Raghuram G., and Luigi Zingales, "The Great Reversals: The politics of Financial Development in the Twentieth Century," Journal of Financial Economics 69, 5-50.

[52] Rodrik, Dani. "Who needs capital account convertibility?" Princeton Essays in International Finance, 207, 1998, pp. 55-65.

[53] Rodrik, Dani, 2000, "Governing the Global Economy: Does One Architectural Style Fit All? In S. Collins and R. Lawrence, eds., Brookings Trade Forum 1999, Brookings Institution, Washington, DC.

[54] Schmukler, Sergio L., 2003, "Financial Globalization: Gain and Pain for Developing Countries," World Bank Working Paper.

[55] Senbet, L., 1979, International capital market equilibrium and the multinational firm financing and investment policies, Journal of Financial and Quantitative Analysis 14, 455-480.

[56] Stapleton, Richard, and Marti Subrahmanyam, 1977, Market imperfections, capital market equilibrium, and corporate finance, Journal of Finance 32, 307-319.

[57] Stiglitz, Joseph. Globalization and Its Discontents. W.W. Norton, New York, (2002). 
[58] Stulz, Rene M., 1981a, A model of international asset pricing, Journal of Financial Economics $9,383-403$.

[59] Stulz, Rene M. "On the Effects of Barriers to International Investment." The Journal of Finance 36:4 (September 1981), 923-934.

[60] Stulz, René M., 1999a, International portfolio flows and security markets, in Martin Feldstein, ed.: International Capital Flows, University Chicago Press, Chicago, Illinois.

[61] Stulz, René M., 1999b, Globalization and the cost of equity capital, Working paper, The New York Stock Exchange (NYSE Working Paper 99-02).

[62] Stulz, René M., 2005, "The Limits of Financial Globalization," Journal of Finance, forthcoming.

[63] Stulz, René M., Walter Wasserfallen, 1995, "Foreign Equity Investment Restrictions, Capital Flight, and Shareholder Wealth Maximization: Theory and Evidence," The Review of Financial Studies Vol. 8, no. 4, pp. 1019-1057.

[64] Subrahmanyam, M. G., 1975a, On the optimality of international capital market integration, Journal of Financial Economics 2, 3-28.

[65] Subrahmanyam, M. G., 1975b, International capital market equilibrium and investor welfare with unequal interest rates, in E. J. Elton and M. J. Gruber, eds.: International Capital Markets (North Holland, Amsterdam).

[66] Summers, Lawrence H. "International Financial Crises: Causes, Prevention, and Cures," American Economic Review, 2000, Vol. 90, No. 2, pp. 1-16.

[67] Tadesse, Solomon, 2003, "Financial Architecture and Economic Performance: International Evidence," Journal of Financial Intermediation, Vol. 11. (See SSRN Announcement).

[68] Tesar, Linda L., and Ingrid M. Werner, 1998, The internationalization of securities markets since the 1987 crash; in Robert E. Litan and Anthony M. Santomero, eds.: Brookings-Wharton Papers on Financial Services (Brookings Institution Press, Washington). 
[69] van Wincoop, Eric, 1994, "Welfare Gains from International Risk Sharing," Journal of Monetary Economics 34, 175-200. 
Figure 1. Boundaries of Participation Set of Domestic Investors under Complete Segmentation as a Function of Domestic Participation Cost, $k_{d}^{d}$. Two cases of domestic idiosyncratic volatility (error variance) are shown: "Low," $\sigma_{\varepsilon_{d}}^{2}=0.1$ (red), and "High," $\sigma_{\varepsilon_{d}}^{2}=1.0$ (blue). High idiosyncratic volatility diminishes the set of participating agents because the benefits from participation are lower. Other parameter values are: $a=0.5, \delta=0.99$. Domestic economy: $b_{d}^{\min }=-4, b_{d}^{\max }=5, \bar{e}^{h}=b_{d}^{h}$ $\forall h \in \mathcal{D}, W_{0}^{h}=2 \forall h \in \mathcal{D}, \sigma_{\varepsilon_{d}^{h}}^{2}=1 \forall h \in \mathcal{D}, k_{d}^{d}=0.55, R_{d}=1, \bar{z}_{d}=1, \beta_{d}=1$. Foreign economy: $b_{f}^{\min }=-2, b_{f}^{\max }=4, \bar{e}^{h}=b_{f}^{h} \forall h \in \mathcal{F}, W_{0}^{h}=2 \forall h \in \mathcal{F}, \sigma_{\varepsilon_{f}^{h}}^{2}=1 \forall h \in \mathcal{F}, k_{f}^{f}=0.01, R_{f}=1, \bar{z}_{f}=1$, $\beta_{f}=1, \sigma_{\varepsilon_{f}}^{2}=1$.

Figure 2. The Set of Domestic Participating Agents. The $x$-axis is the agent's factor loading, $b_{d}^{h}$. The cases shown are: Complete Segmentation (blue), Partial Liberalization when initial center of mass is positive (green), and Partial Liberalization when initial center of mass is negative (red).

Figure 3. Change in Aggregate Welfare of Domestic Type A Investors as a Function of Domestic Participation Cost. Three cases of idiosyncratic risk of the domestic asset, $\sigma_{\varepsilon_{d}}^{2}$, are shown. Parameter values are: "High" error variance $\sigma_{\varepsilon_{d}}^{2}=1$ (blue); "Intermediate," $\sigma_{\varepsilon_{d}}^{2}=0.7$ (green); "Low," $\sigma_{\varepsilon_{d}}^{2}=0.1$ (red). Other parameter values are the same as for Figure 1.

Figure 4. Change in Aggregate Welfare of Domestic Type A Investors as a Function of Foreign Participation Cost. Three cases of idiosyncratic risk of the domestic asset, $\sigma_{\varepsilon_{d}}^{2}$, are shown. Parameter values are: "High" error variance $\sigma_{\varepsilon_{d}}^{2}=1$ (blue); "Intermediate," $\sigma_{\varepsilon_{d}}^{2}=0.7$ (green); "Low," $\sigma_{\varepsilon_{d}}^{2}=0.1$ (red). Other parameter values are the same as for Figure 1, except that domestic participation cost is fixed, $k_{d}^{d}=0.55$.

Figure 5. Change in Aggregate Domestic Welfare as a Function of Foreign Participation Cost. Three cases of idiosyncratic risk of the domestic asset, $\sigma_{\varepsilon_{d}}^{2}$, are shown. Parameter values are: "High" error variance $\sigma_{\varepsilon_{d}}^{2}=1$ (blue); "Intermediate," $\sigma_{\varepsilon_{d}}^{2}=0.7$ (green); "Low," $\sigma_{\varepsilon_{d}}^{2}=0.1$ (red). Other parameter values are the same as for Figure 1, except $b_{d}^{\max }=5.5$; domestic participation fee is fixed, $k_{d}^{d}=0.55$.

Figure 6. Change in Aggregate Domestic Welfare as a Function of Domestic Participation Cost. Three cases of idiosyncratic risk of the domestic asset, $\sigma_{\varepsilon_{d}}^{2}$, are shown. Parameter values are: "High" error variance $\sigma_{\varepsilon_{d}}^{2}=1$ (blue); "Intermediate," $\sigma_{\varepsilon_{d}}^{2}=0.7$ (green); "Low," $\sigma_{\varepsilon_{d}}^{2}=0.1$ (red). 
Other parameter values are the same as for Figure 1, except $b_{d}^{\max }=5.5$; foreign participation fee is fixed: $k_{f}^{f}=0.1$.

Figure 7. Utility of Domestic Agents Under Complete Segmentation and Partial Liberalization. The $x$-axis is the agent's factor loading, $b_{d}^{h}$. The $y$-axis is the level of lifetime utility of consumption. Blue line is utility under segmentation; green line is utility under partial liberalization. Parameter values are the same as for Figure 1 , except $b_{d}^{\max }=5.5$; foreign participation fee is fixed: $k_{f}^{f}=0.1$; domestic error variance is $\sigma_{\varepsilon_{d}}^{2}=0.1$.

Figure 8. Percent Change in Aggregate Utility of Domestic Agents. The $y$-axis is the percent change in level of aggregate utility of domestic agents. Parameter values are: "High" error variance $\sigma_{\varepsilon_{d}}^{2}=1$ (blue); "Intermediate," $\sigma_{\varepsilon_{d}}^{2}=0.7$ (green); "Low," $\sigma_{\varepsilon_{d}}^{2}=0.1$ (red). Other parameter values are the same as for Figure 1, except $b_{d}^{\max }=5.5$; domestic participation fee is fixed, $k_{d}^{d}=0.55$.

Figure 9. Percent Change in Utility of Domestic Agents. The $x$-axis is the agent's factor loading, $b_{d}^{h}$. The $y$-axis is the percent change in level of lifetime utility of consumption. Parameter values are the same as for Figure 7.

Figure 10. Equivalent Wealth Variation for Domestic Economy as a Function of Domestic Participation Cost. Two cases of domestic idiosyncratic volatility are shown: "Low," $\sigma_{\varepsilon_{d}}^{2}=0.1$ (red), and "Intermediate," $\sigma_{\varepsilon_{d}}^{2}=0.7$ (green). Parameter values are the same as for Figure 7.

Figure 11. Equivalent Wealth Variation for Individual Domestic Agents. The $x$-axis is the agent's factor loading $b_{d}^{h}$. The $y$-axis shows percent change in initial wealth that makes the agent indifferent between segmentation and liberalization. A positive value indicates that under liberalization an agent needs to receive additional wealth to compensate for utility loss. Two cases of domestic idiosyncratic volatility are shown: "Low," $\sigma_{\varepsilon_{d}}^{2}=0.1$ (red), and "Intermediate," $\sigma_{\varepsilon_{d}}^{2}=0.7$ (green). Parameter values are the same as for Figure 7. 


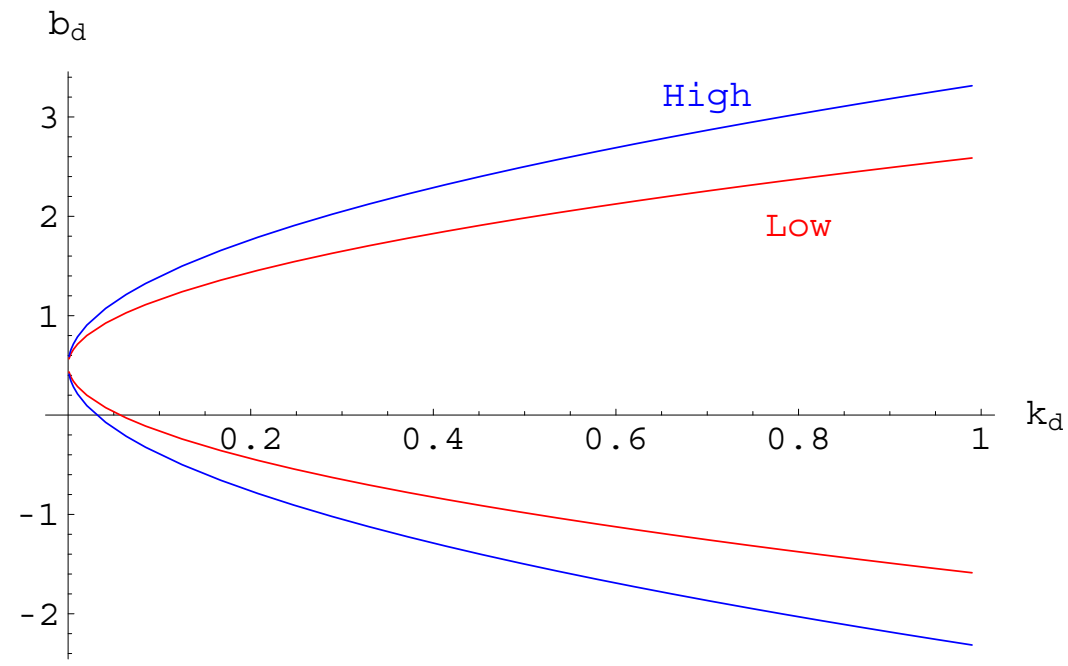

Figure 1: Boundaries of Participation Set of Domestic Investors under Complete Segmentation as a Function of Domestic Participation Cost, $k_{d}^{d}$. Two cases of domestic idiosyncratic volatility (error variance) are shown: "Low," $\sigma_{\varepsilon_{d}}^{2}=0.1$ (red), and "High," $\sigma_{\varepsilon_{d}}^{2}=1.0$ (blue). High idiosyncratic volatility diminishes the set of participating agents because the benefits from participation are lower. Other parameter values are: $a=0.5, \delta=0.99$. Domestic economy: $b_{d}^{\min }=-4, b_{d}^{\max }=5$, $\bar{e}^{h}=b_{d}^{h} \forall h \in \mathcal{D}, W_{0}^{h}=2 \forall h \in \mathcal{D}, \sigma_{\varepsilon_{d}^{h}}^{2}=1 \forall h \in \mathcal{D}, k_{d}^{d}=0.55, R_{d}=1, \bar{z}_{d}=1, \beta_{d}=1$. Foreign economy: $b_{f}^{\min }=-2, b_{f}^{\max }=4, \bar{e}^{h}=b_{f}^{h} \forall h \in \mathcal{F}, W_{0}^{h}=2 \forall h \in \mathcal{F}, \sigma_{\varepsilon_{f}^{h}}^{2}=1 \forall h \in \mathcal{F}, k_{f}^{f}=0.01$, $R_{f}=1, \bar{z}_{f}=1, \beta_{f}=1, \sigma_{\varepsilon_{f}}^{2}=1$. 


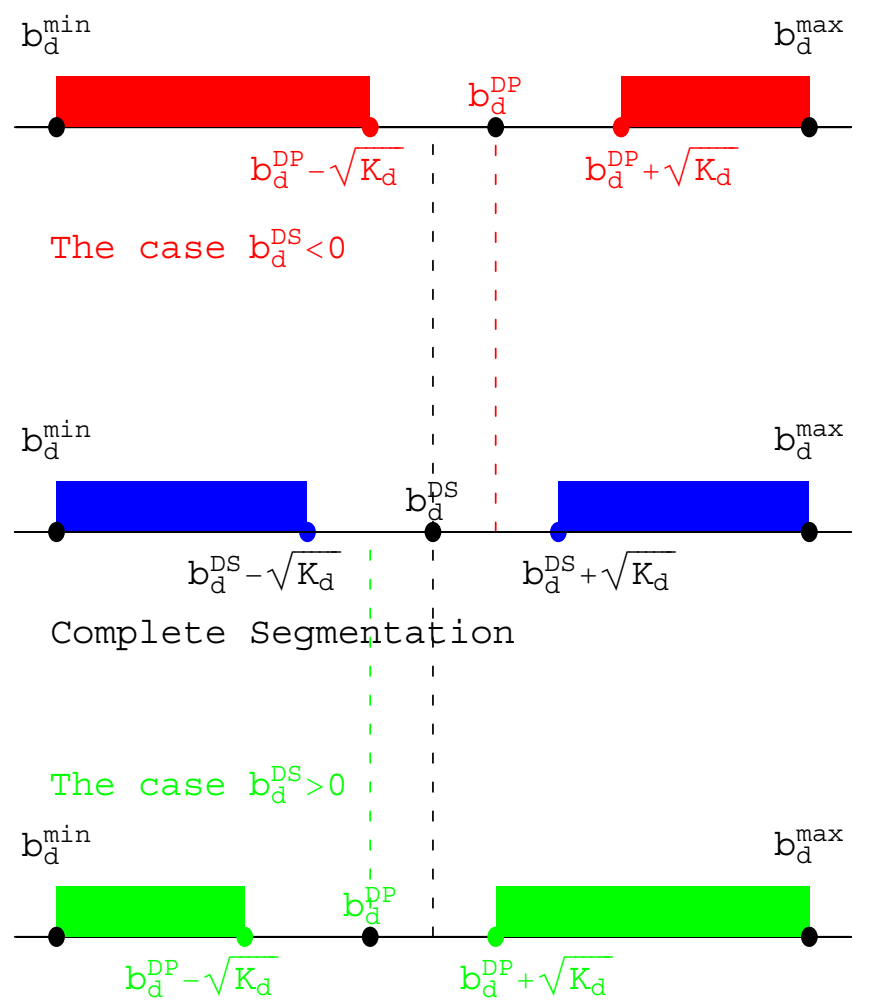

Figure 2: The Set of Domestic Participating Agents. The $x$-axis is the agent's factor loading, $b_{d}^{h}$. The cases shown are: Complete Segmentation (blue), Partial Liberalization when initial center of mass is positive (green), and Partial Liberalization when initial center of mass is negative (red). 


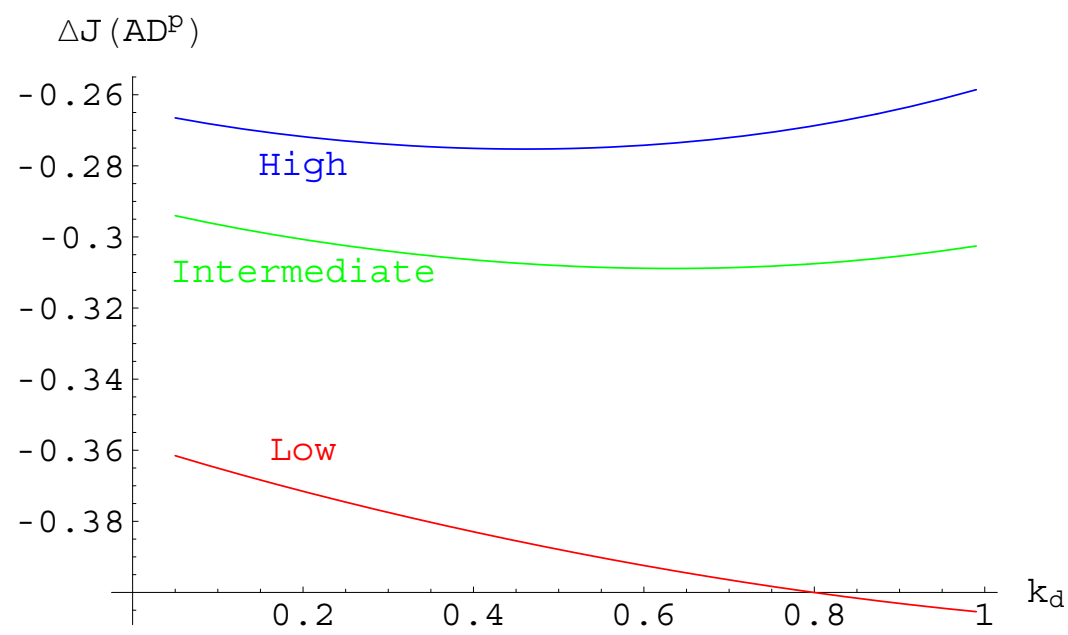

Figure 3: Change in Aggregate Welfare of Domestic Type A Investors as a Function of Domestic Participation Cost. Three cases of idiosyncratic risk of the domestic asset, $\sigma_{\varepsilon_{d}}^{2}$, are shown. Parameter values are: "High" error variance $\sigma_{\varepsilon_{d}}^{2}=1$ (blue); "Intermediate," $\sigma_{\varepsilon_{d}}^{2}=0.7$ (green); "Low," $\sigma_{\varepsilon_{d}}^{2}=0.1$ (red). Other parameter values are the same as for Figure 1. 


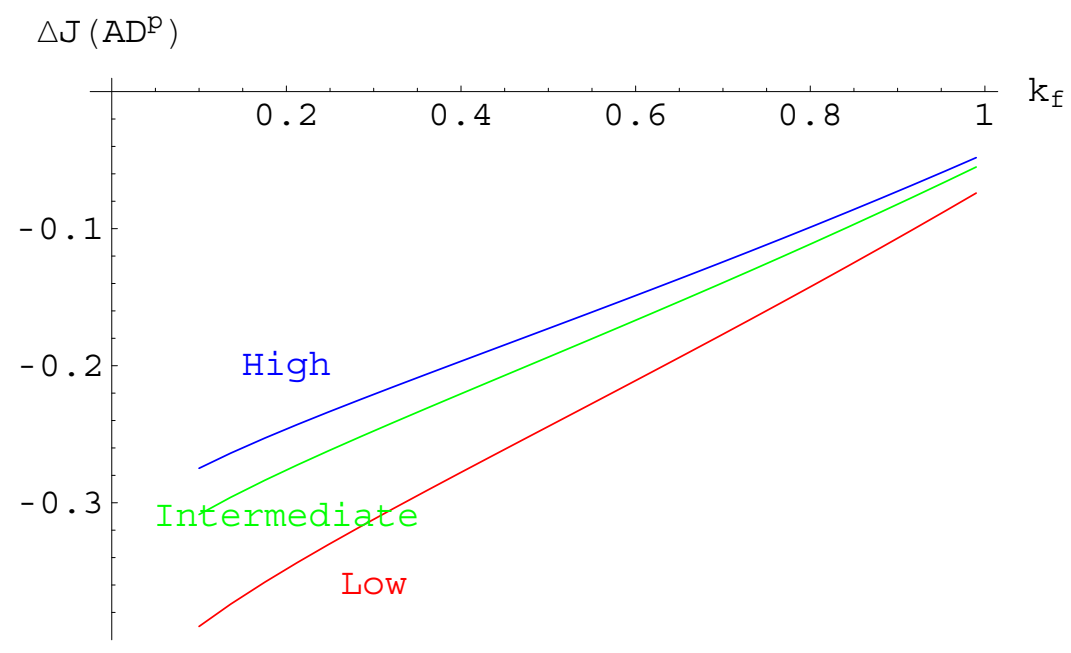

Figure 4: Change in Aggregate Welfare of Domestic Type A Investors as a Function of Foreign Participation Cost. Three cases of idiosyncratic risk of the domestic asset, $\sigma_{\varepsilon_{d}}^{2}$, are shown. Parameter values are: "High" error variance $\sigma_{\varepsilon_{d}}^{2}=1$ (blue); "Intermediate," $\sigma_{\varepsilon_{d}}^{2}=0.7$ (green); "Low," $\sigma_{\varepsilon_{d}}^{2}=0.1$ (red). Other parameter values are the same as for Figure 1, except that domestic participation cost is fixed, $k_{d}^{d}=0.55$. 


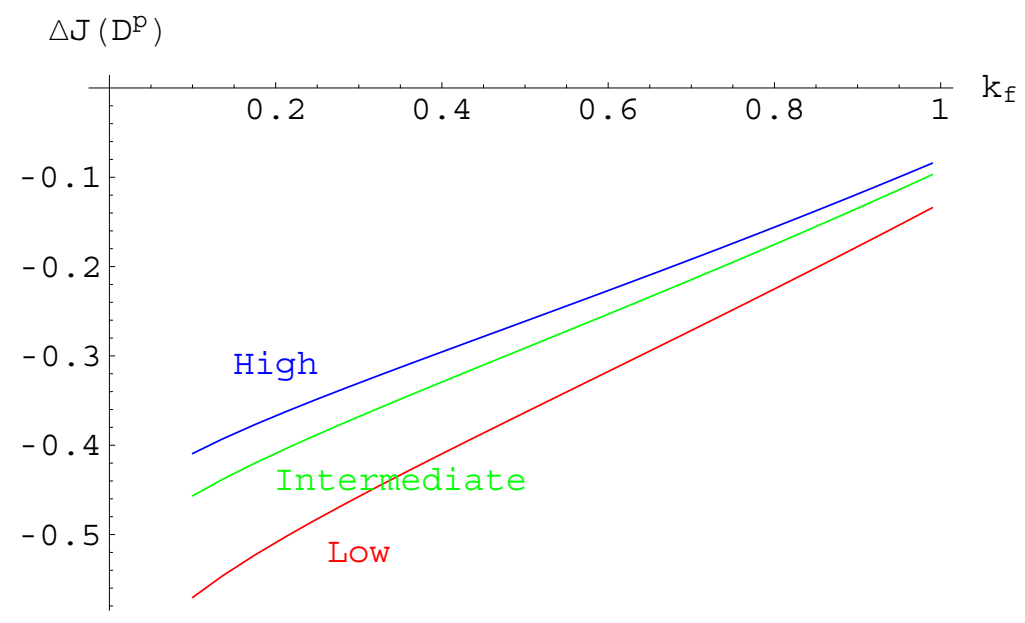

Figure 5: Change in Aggregate Domestic Welfare as a Function of Foreign Participation Cost. Three cases of idiosyncratic risk of the domestic asset, $\sigma_{\varepsilon_{d}}^{2}$, are shown. Parameter values are: "High" error variance $\sigma_{\varepsilon_{d}}^{2}=1$ (blue); "Intermediate," $\sigma_{\varepsilon_{d}}^{2}=0.7$ (green); "Low," $\sigma_{\varepsilon_{d}}^{2}=0.1$ (red). Other parameter values are the same as for Figure 1, except $b_{d}^{\max }=5.5$; domestic participation fee is fixed, $k_{d}^{d}=0.55$. 


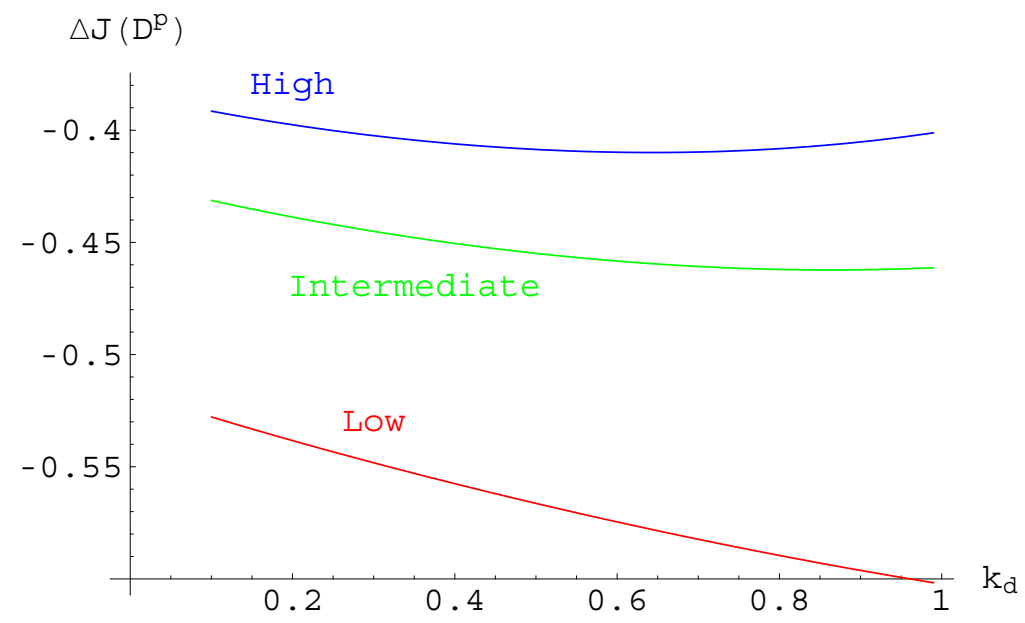

Figure 6: Change in Aggregate Domestic Welfare as a Function of Domestic Participation Cost. Three cases of idiosyncratic risk of the domestic asset, $\sigma_{\varepsilon_{d}}^{2}$, are shown. Parameter values are: "High" error variance $\sigma_{\varepsilon_{d}}^{2}=1$ (blue); "Intermediate," $\sigma_{\varepsilon_{d}}^{2}=0.7$ (green); "Low," $\sigma_{\varepsilon_{d}}^{2}=0.1$ (red). Other parameter values are the same as for Figure 1, except $b_{d}^{\max }=5.5$; foreign participation fee is fixed: $k_{f}^{f}=0.1$. 


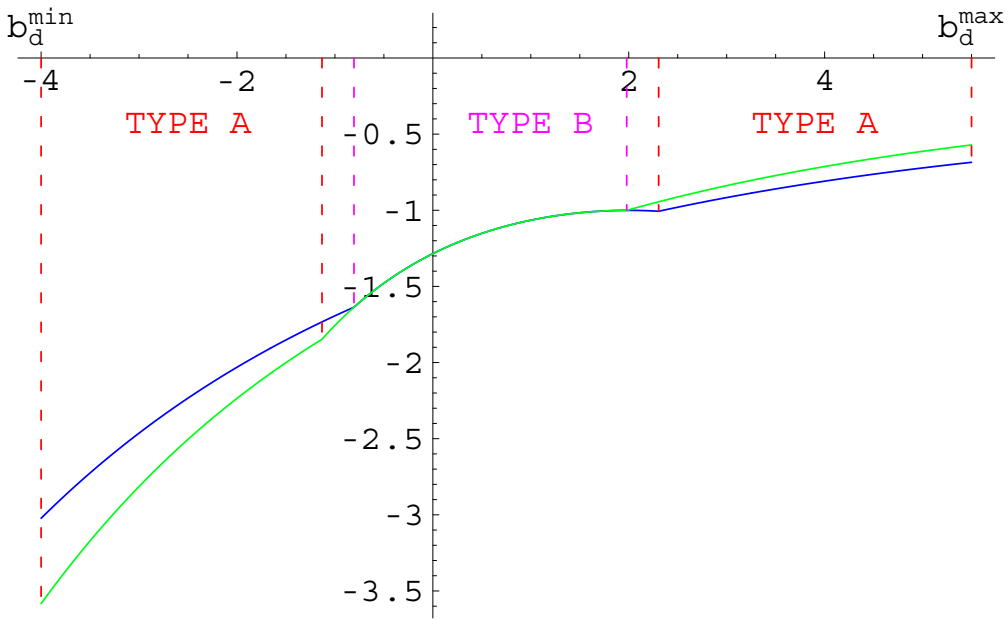

Figure 7: Utility of Domestic Agents Under Complete Segmentation and Partial Liberalization. The $x$-axis is the agent's factor loading, $b_{d}^{h}$. The $y$-axis is the level of lifetime utility of consumption. Blue line is utility under segmentation; green line is utility under partial liberalization. Parameter values are the same as for Figure 1, except $b_{d}^{\max }=5.5$; foreign participation fee is fixed: $k_{f}^{f}=0.1$; domestic error variance is $\sigma_{\varepsilon_{d}}^{2}=0.1$.

○Change $J\left(D^{p}\right)$

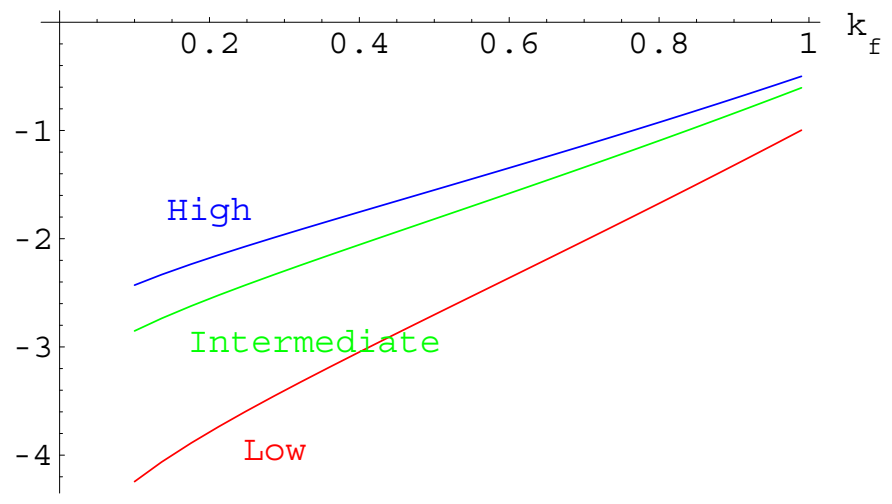

Figure 8: Percent Change in Aggregate Utility of Domestic Agents. The $y$-axis is the percent change in level of aggregate utility of domestic agents. Parameter values are: "High" error variance $\sigma_{\varepsilon_{d}}^{2}=1$ (blue); "Intermediate," $\sigma_{\varepsilon_{d}}^{2}=0.7$ (green); "Low," $\sigma_{\varepsilon_{d}}^{2}=0.1$ (red). Other parameter values are the same as for Figure 1, except $b_{d}^{\max }=5.5$; domestic participation fee is fixed, $k_{d}^{d}=0.55$. 


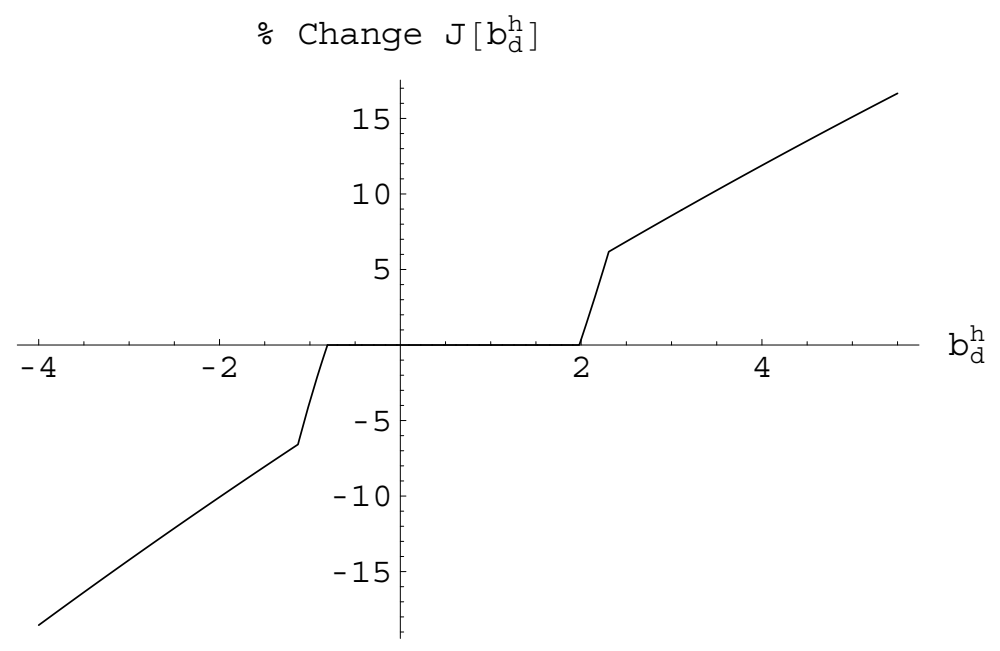

Figure 9: Percent Change in Utility of Domestic Agents. The $x$-axis is the agent's factor loading, $b_{d}^{h}$. The $y$-axis is the percent change in level of lifetime utility of consumption. Parameter values are the same as for Figure 7.

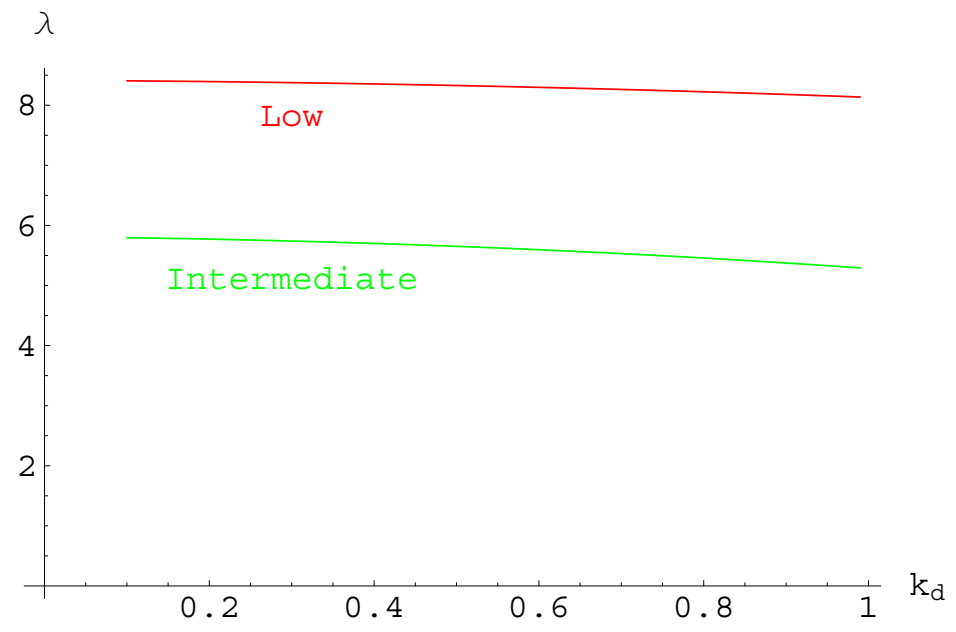

Figure 10: Equivalent Wealth Variation for Domestic Economy as a Function of Domestic Participation Cost. Two cases of domestic idiosyncratic volatility are shown: "Low," $\sigma_{\varepsilon_{d}}^{2}=0.1$ (red), and "Intermediate," $\sigma_{\varepsilon_{d}}^{2}=0.7$ (green). Parameter values are the same as for Figure 7. 


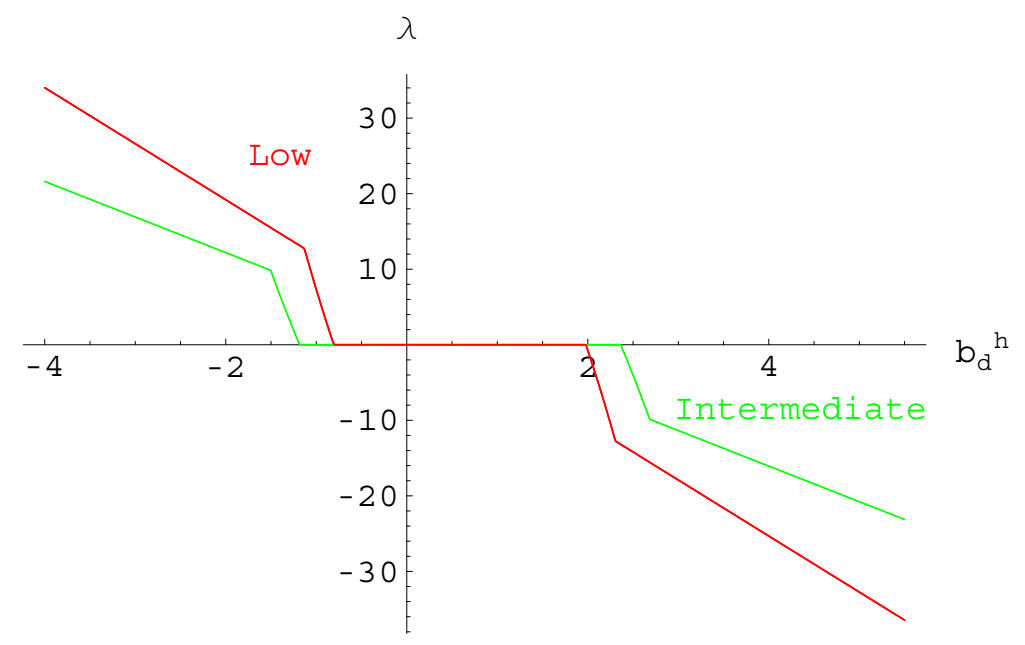

Figure 11: Equivalent Wealth Variation for Individual Domestic Agents. The $x$-axis is the agent's factor loading $b_{d}^{h}$. The $y$-axis shows percent change in initial wealth that makes the agent indifferent between segmentation and liberalization. A positive value indicates that under liberalization an agent needs to receive additional wealth to compensate for utility loss. Two cases of domestic idiosyncratic volatility are shown: "Low," $\sigma_{\varepsilon_{d}}^{2}=0.1$ (red), and "Intermediate," $\sigma_{\varepsilon_{d}}^{2}=0.7$ (green). Parameter values are the same as for Figure 7. 